\title{
Interannual variations in the population biology and productivity of Euphausia pacifica in Barkley Sound, Canada, with special reference to the 1992 and 1993 warm ocean years
}

\author{
R. W. Tanasichuk* \\ Department of Fisheries and Oceans, Pacific Biological Station, Nanaimo, British Columbia V9R 5K6, Canada
}

\begin{abstract}
I monitored the size composition, abundance, growth, reproductive biomass and productivity characteristics of Euphausia pacifica in Barkley Sound, Canada, from March 1991 through March 1997. Sea temperatures were anomalously warm in 1992 (El Niño Southern Oscillation, ENSO) and in 1993; the strongest upwelling over the study period occurred in 1992. Mean annual E. pacifica larval abundance was 6 times greater in 1992 than in 1991, the pre-ENSO year. Adult abundance in 1992 and 1993 was twice that for 1991 due to the strong recruitment moving through the population. Larval abundance fluctuated substantially since the warming while adult abundance returned to pre-ENSO levels in 1994. Growth conditions, as indicated by variations in the condition factor, did not vary significantly over the 6 yr study period. Length-at-maturity increased over the spawning season but interannual variations were too small to influence adult abundance. The sex ratio fluctuated randomly around a grand mean of 0.56 males within and between years. I present a procedure for defining spawning events as a function of larval development time and its variability. I found a number of discrete spawnings annually and suggest that there has been no change in spawning frequency or duration over the study period. 1 found no significant change in the size of any larval stage over the study period. The relationship between parental and larval abundance follows a Ricker stock-recruit relationship; larval abundance decreased at high parental abundances. Mean annual larval biomass and productivity (growth + moult) ranged from being the same as to 9 times greater than 1991 levels. Mean adult biomass was 1.2 and 2 times greater in 1992 and 1993 respectively than in 1991; productivity was 1.8 and 2.3 times higher in 1992 and 1993 respectively and has returned to pre-ENSO levels. $P$ : $B$ ratios for total production ranged from 55 to 89 and from 8.6 to 12.4 for larvae and adults respectively. Population $P: B$ ratios fluctuated between 10.7 and 23.3
\end{abstract}

KEY WORDS: Euphausia pacifica - Euphausiid Population biology P Productivity Ocean variability

\section{INTRODUCTION}

Mauchline (1980) describes euphausiids as an often abundant and conspicuous component of marine macrozooplankton, where they can play a significant role in the flow of energy and matter in pelagic food webs. Euphausia pacifica appears then to be a typical euphausiid species because of its abundance in midand higher latitude Pacific coastal ecosystems and its importance to energy flow within some marine ecosys-

•E-mail: tanasichukr@dfo-mpo.gc.ca tems. Smiles \& Pearcy (1971) reported that E. pacifica is preyed upon by a number of invertebrate, fish and marine mammal species. Brodeur \& Pearcy (1992) refer to the importance of euphausiids, including E. pacifica, to the coastal upwelling zone off Oregon and Washington, USA. Tanasichuk et al. (1991) found that euphausiids (E. pacifica, Thysanoessa spinifera) are the most important food item for commercially important fish species in a productive fishing area along the southwest coast of Vancouver Island, Canada. Nemoto (1957) described the importance of E. pacifica as food for fish and whale species in Japanese waters. 
There have been a number of studies on the biology of Euphausia pacifica, but few have considered the influence of environmental variability. Research on $E$. pacifica ranges from the early work by Lasker (1966), who investigated growth and respiration in the laboratory, to Brinton's (1976) exhaustive study of the population biology in the California Bight over 4 years and Ross' series of reports (Ross 1981, 1982a, b, Ross et al. 1982) on reproductive biology and energetics, through to the most recent work by Iguchi \& Ikeda (1995) on temperature effects on growth and metabolism. Brinton (1976) endeavoured to select a series of consecutive years (1953 to 1956) from the CalCOFI sampling time series when variability was minimal. His purpose was to develop baseline information on E. pacifica population biology which could be used to measure the effects of oceanic variability. The only study which describes an effect of environmental variation on E. pacifica is that of Brinton \& Reid (1986). They found that, while showing conservative biological responses to recent variations in ocean climate, individual euphausiid species can locally undergo 5to 10 -fold interannual changes in biomass. In their case, the southern species (Nyctiphanes simplex) dominated in warm times and the northern species ( $E$. pacifica) in cool times. In general, there are surprisingly few studies which examine the influence of interannual variations in ocean climate on the biology and productivity of euphausiids. Drobysheva (1987) reported results for Thysanoessa inermis and $T$. raschii in the Barents Sea over a 30 yr period which are similar to those presented by Brinton \& Reid (1986). Most recently, Loeb et al. (1997) described how variations in winter ice condition may influence year-class strength in E. superba.

The goal of this study was to monitor the population biology and productivity of Euphausia pacifica, to hopefully track the responses of this euphausid through a period of anomalous change in ocean temperature. There was substantial ocean warming in 1992 (ENSO) and 1993. The Canadian Department of Fisheries and Oceans began studying the waters along the southwest coast of Vancouver Island (La Perouse Bank area) in 1985 to determine how changes in ocean climate affect fish production. The results presented here complement this long-term program by showing how changes in ocean climate affect E. pacifica, an important food item for many commercially important fish species.

\section{MATERIALS AND METHODS}

I have been sampling euphausiids in Barkley Sound since March 1991 (Fig. 1). I chose Barkley Sound because it can be sampled conveniently using a small boat virtually all through the year, and it is adjacent to the La Perouse Bank area.

Euphausiids were collected during 42 cruises. There are 4 sampling stations which collectively reflect the bathymetric and circulation characteristics of the Sound (Fig. 1). Cruises were made 9 times annually between March 1991 and 1994 to define accurately the seasonal growth, abundance, size composition and reproduction patterns. Since then, I collected samples 5 times a year (January, March, June, August and October) to monitor interannual variations.

Samples were taken at night using obliquely towed bongo nets $(60 \mathrm{~cm}$ mouth diameter, $330 \mu \mathrm{m}$ mesh nets) which traveled to within $10 \mathrm{~m}$ of the bottom. All samples were preserved in 5\% formalin. A subsample of adult-sized euphausiids (>9 mm total length) from one codend was taken for surplus energy analyses when the hepatopancreas and gonad were weighed. The entire sample from the other

Fig. 1. Study area. C (Coaster Channel) $\mathrm{S}$ (Swale Rock), R (Robber's Passage) and $M$ (Mackenzie Anchorage) are Barkley Sound sampling sites. Amphitrite Point shows the lighthouse location. C2, C3: offshore plankton sampling stations. A1: the offshore mooring which provided data for current velocity indices 
cod-end was preserved. This sample was size-fractionated using 250, 500 and $1700 \mu \mathrm{m}$ sieves to separate adults and sub-adults. All adult-sized euphausiids were identified to species and then counted and measured. Individuals from stratified random sub-samples (a maximum of 5 individuals per millimeter length interval) were weighed, sexed and their maturity described (immature: no secondary sexual characters; male: petasma and with or without spermatophores; female: thelycum and unfertilized, fertilized or gravid). All mass measurements were multiplied by 0.20 because Parsons et al. (1984) reported a water content of $80 \%$ for North Pacific euphausiids. Samples of sub-adults were split using a Folsom splitter. The goal was to have 50 calyptopes and furcilia in the split to be analysed. Eggs and nauplii were counted and measured. Calyptopis and furcilia larva were identified to species and stage, and then counted and measured. Larvae were identified using the descriptions presented by Boden (1950) for Euphausia pacifica. E. pacifica larvae were distinguished from Thysanoessa larvae using the key developed in our laboratory. We based this key on the larval descriptions of $T$. spinifera, the other abundant euphausiid species in Barkley Sound, that Summers (1993) presented.

Abundance (no. $\mathrm{m}^{-2}$ ) was estimated from no. $\mathrm{m}^{-3} \times$ tow depth. Volume of water filtered was measured with a TSK flowmeter. Abundance is expressed as the mean over the 4 stations weighted by station-specific volume filtered.

I used log-transformed total length, total mass and ovarian mass estimates to develop cruise-specific length-mass and year-specific total mass-ovarian mass relationships. I measured ovarian mass until 1995 only. Differences were tested using analysis of covariance (ANCOVA). I used the GT-2 method described by Sokal \& Rohlf (1981) to test for the significance of slope and then intercept differences.

I developed a procedure for identifying discrete spawnings using the data presented by Ross (1981) and the effect of temperature on Euphausia pacifica development time described by Iguchi \& Ikeda (1994). Ross presented cumulative percentage plots for $E$. pacifica larvae reared at 8 and $12^{\circ} \mathrm{C}$. I used the sample size and mortality data for $12^{\circ} \mathrm{C}$ to estimate the number of larvae at each stage. By using the daily percentage increase in the number of larvae at a given larval stage, and the sample size information, I calculated the number of larvae attaining a larval stage at a certain age. I used probability plots, as recommended by Wilkinson et al. (1996), to test for normality for age at which a certain larval stage was reached. In those instances where data were normally distributed, I calculated the mean, variance and $95 \%$ confidence limits (Table 1). I assumed, as indicated in Ross (1981), that variability in age at a given larval stage was independent of temperature. Iguchi \& Ikeda (1994) reported that development time was a negative exponential function of temperature. I used the median development times Ross (1981) presented for 8 and $12^{\circ} \mathrm{C}$, and non-linear parameter estimation (SYSTAT 1994), to calculate equations which estimated stage-specific median development time as a function of temperature. By knowing larval stage and sea temperature at Amphitrite Point (see below) over the lifetime of the larva, I back-calculated a temperature-corrected birthdate and assigned $95 \%$ confidence limits to the estimate. Estimates for all larval stages sampled during the study were arranged by increasing birthdate. Instances where confidence limits for any larval stage did not overlap indicated times when there was no spawning.

I estimated growth and moult production between successive sampling dates. Growth production was estimated using the Petrovich method described by Ritz \& Hosie (1982). Although spawnings were not completely continuous (see 'Results'), spawning was considered protracted enough to justify using this procedure. Length-specific mass at each interval was estimated using the cruise-specific length-total mass regression. Length-specific age ( $t$, days) was calculated using the the growth curve (see 'Results') and the equation:

$$
\ln \left(L_{\mathrm{nnt}}-I_{t}\right)=\ln L_{\mathrm{nnf}}+K t_{0}-K t
$$

where $L_{\text {nir }} I_{t}$ and $K$ are the parameters from the von Bertalanffy fit to the growth curve and $t_{0}=0$ (Ricker 1975). I estimated length-specific moult production $P_{m, i}$ as:

$$
P_{m, i}=\left(W_{i} \times N_{i} \times 0.106\right) / I P
$$

(Sameoto 1976) where $i$ is length interval, $W$ is lengthspecific dry mass, $N$ is the length-specific abundance

Table 1 Euphausia pacifica. Estimated age (days, mean \pm $2 \mathrm{SE}$ ) at development stage for euphausiids reared at $12^{\circ} \mathrm{C}$

\begin{tabular}{|lc|}
\hline Stage & Age \\
\hline C1 & $7 \pm 1.5$ \\
C2 & $11 \pm 4.0$ \\
F3 & $14^{*}$ \\
F2 & $19 \pm 6.5$ \\
F3 & $22 \pm 13.2$ \\
F4 & $27^{\circ}$ \\
F5 & $35 \pm 3.0$ \\
F6 & $37^{\mathrm{b}}$ \\
F7 & $38 \pm 6.5$ \\
J & $42 \pm 11.8$ \\
"Median values given where data are not normally distrib- \\
uted & $47 \pm 6.0$ \\
'Estimated as midpoint of F4 and F6 ages \\
\hline
\end{tabular}




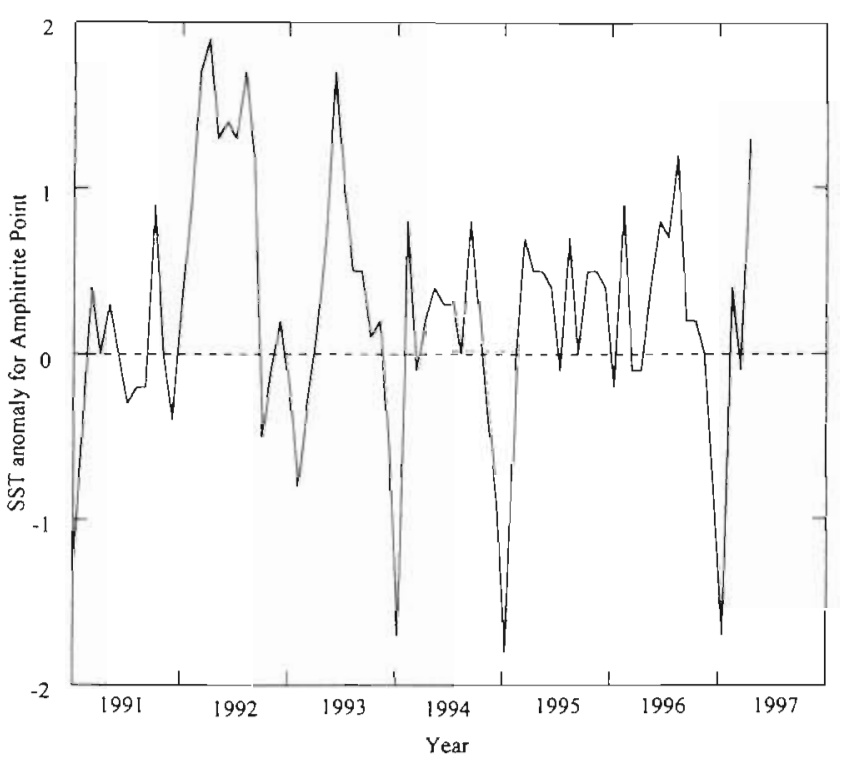

Fig. 2. Monthly sea surface temperature anomalies measured at Amphitrite Point lighthouse

and $I P$ is the intermoult period. Jerde \& Lasker (1966) found that Euphausia pacifica moults represented about $10.6 \%$ of the dry body mass. IP was estimated using the equation Iguchi \& Ikeda (1995) developed for E. pacifica:

$$
\log _{10} I P=0.0321 \times L+10^{0.0340-0.0435 T}
$$

where $L$ is length and $T$ is the mean sea temperature at Amphitrite Point (see below) between sampling events. I did not estimate egg production because there is no conclusive information on E. pacifica fecundity (brood size $\times$ number of spawnings) (see 'Discussion').

All annual estimates were made considering a year to begin in March and end in February. This was because spawnings in a calendar year began in March, which I considered to signify the beginning of a new 'biological year'.

Sea surface temperature data came from Amphitrite Point. This is a lighthouse station located 20 nautical miles west of the study area (Fig. 1). I used the current velocity index developed by Thomson \& Ware (1996) to describe the intensity of summer upwelling over the study period.

\section{RESULTS}

\section{Sea conditions over the study period}

An appropriate examination of the influence of variations in sea temperature must begin with an understanding of how sea temperature fluctuated over the study period. Fig. 2 shows the sea temperature anomalies at Amphitrite Point. Sea temperatures were warmer than average from 1992 through 1996. There were large positive anomalies in 1992 and 1993 and large negative anomalies during the winters of $1993-$ 94, 1994-95 and 1996-97

Trends in the current velocity index are shown in Fig. 3. Although the data record is somewhat incomplete, it shows the strongest upwelling during the study period occurred in 1992. The strongest downwelling event occurred in the winter of 1994-95.

\section{Sampling bias}

I anticipated 3 potential sources of bias: (1) betweenstation variability, (2) the effect of reduced sampling intensity and (3) differences between samples collected in Barkley Sound and offshore, in the La Perouse study area. I found relatively few instances of substantial between-station variability for a given cruise. Fig. 4 shows the time series of abundance for all sampling stations. There were 5 instances where there were large differences in abundances between stations. I excluded these samples from any calculations which considered abundance. Next, the reduction in sampling intensity could potentially bias the estimates of mean annual abundance, biomass and productivity by missing peaks and/or troughs in trends. Fig. 5 shows the mean annual abundance estimates for larval and adult Euphausia pacifica. Means for the years 1991 through 1993 were estimated using all sampling data, and then using data

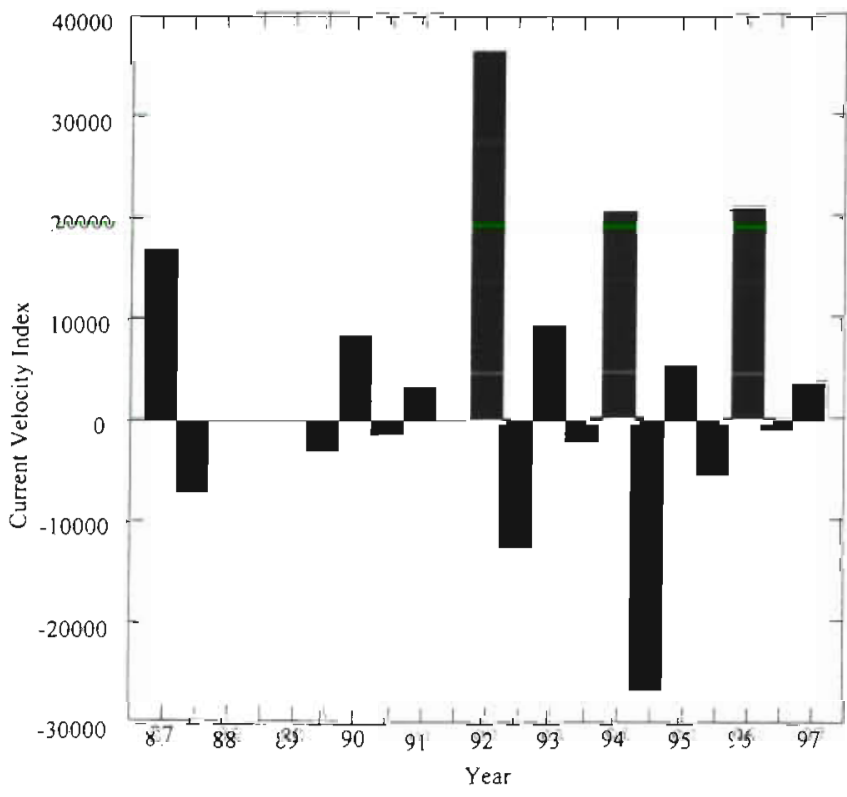

Fig. 3. Current velocity index. Positive values indicate upwelling. Bars show intensity 
for the 5 months (January, March, June, August and October) which were sampled in all years. These figures show that any bias due to the reduced sampling intensity is much smaller than the interannual variations in abundance. Therefore, the reduction in sampling intensity would not affect the comparison of abundance, biomass or productivity between years. Finally, I compared the size distributions and abundances of adult $E$. pacifica collected in Barkley Sound with those from samples collected at the offshore stations (Fig. 1). These offshore stations are occupied by a long-term coastal zooplankton sampling program (COPRA). Samples are collected whenever research vessels are in the vicinity; unfortunately, there were only 3 instances when samples were collected at both stations at night, using obliquely towed bongo nets, and near times when I collected samples in Barkley Sound. Figs. 6 \& 7 shows comparisons of abundances and size-frequency distributions respectively. The abundance data suggest good agreement between the Barkley Sound and offshore samples. Results of a log-linear model analysis showed that location had a significant effect on size-frequency distributions in 1995 only. Therefore I concluded that samples collected in Barkley Sound in the La Perouse study area show that the same population is being sampled.

\section{Size composition and abundance}

Mean annual abundance estimates are given in Table 2 and larval and adult abundance trends are shown in Fig. 8. Larval abundance increased by 6 times in 1992 and fluctuated after. Abundances in 1993 through 1996 were approximately 3 times that in 1991 . the pre-ENSO year. Adult abundance doubled in 1992 and remained high in 1993 before returning to 1991 levels. Length-frequency histograms are presented in Fig. 9. Larvae $(<10 \mathrm{~mm})$ were present continuously, although in some winter months only as larger ones. Adult length-frequency distributions were multimodal, with inconsistent separation among distributions. Fig. 10 shows changes in abundance by arbitrary adult size categories. The increases in adult abundance in 1992 and 1993 appear to be due to the exceptionally strong recruitment in 1992 moving through the population. It appears larger adults $(>20 \mathrm{~mm})$ were present more consistently in 1991 and 1992, and were virtually absent in later years.

\section{Growth}

Because of the protracted spawning seasons in all years, I could only confidently develop a growth trajec-

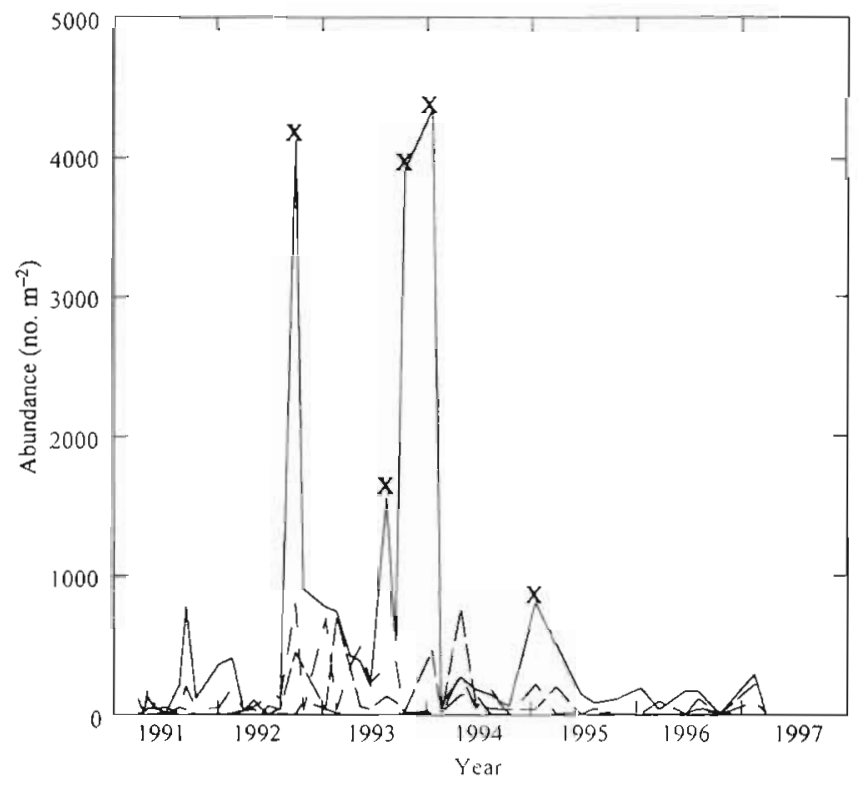

Fig. 4. Euphausia pacifica. Abundance of adults at each Barkley Sound sampling station. X: aberrant samples

tory (Fig. 11) for the progression of a distinct mode from January 1992 to March 1993 (Fig. 9). I accepted the growth trajectory because the accompanying abundance trajectory showed a non-linear reduction over time, which is biologically reasonable. I used the non-linear parameter estimation procedure in SYSTAT and fit length-at-time $\left(L_{t}\right.$, where $t$ is days since the

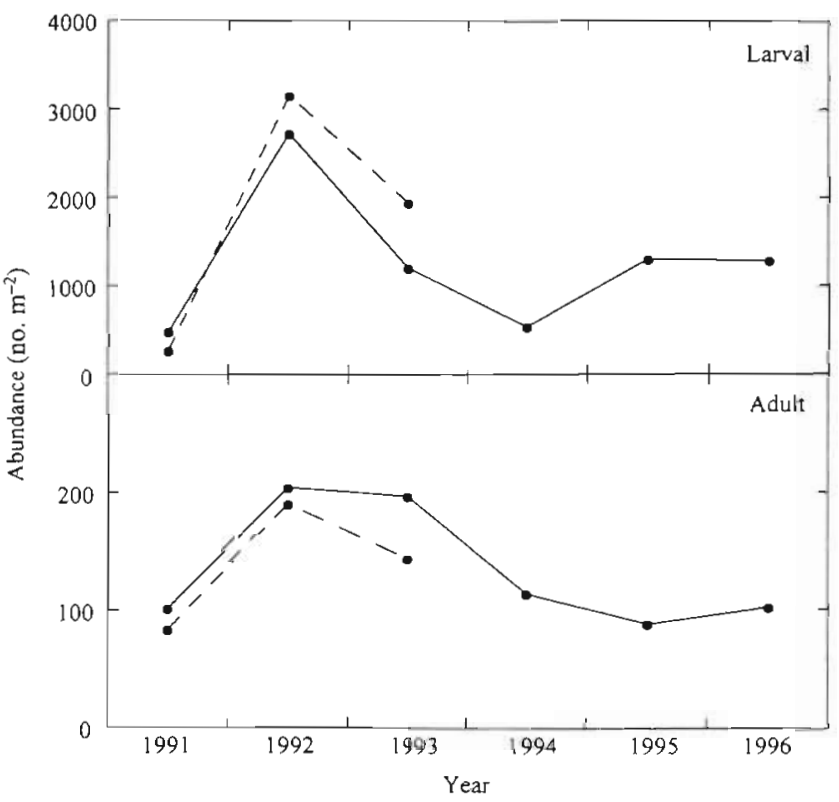

Fig. 5. Euphausia pacifica. Mean annual larval and adult abundance based on data for all samples within the MarchFebruary sampling year (---) and data for March, June, August, October and January samples (-) 


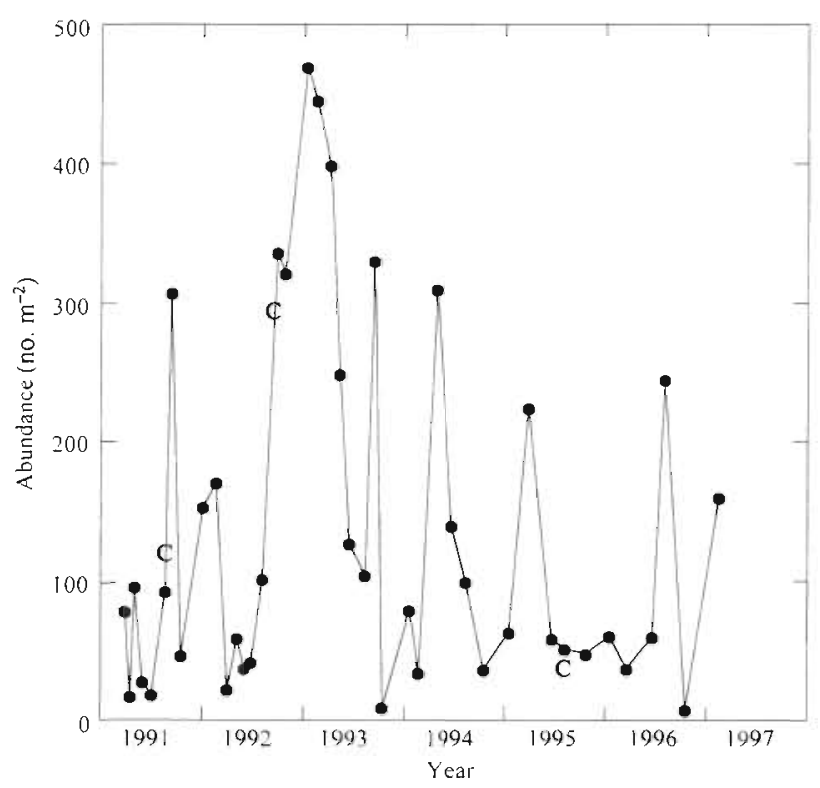

Fig. 6. Euphausia pacifica. Adult abundance for Barkley Sound (-) and offshore COPRA (C) sampling stations

mode appeared) data to a von Bertalanffy growth function. The equation was:

$$
L_{t}=30.19\left(1-\mathrm{e}^{-0.0085 t}\right), \mathrm{R}^{2}=0.98, \mathrm{p}<0.0001
$$

I evaluated interannual variations in growth conditions using the adjusted mean dry mass (Fig. 12), which is based on an ANCOVA of the total lengthtotal mass regressions. Results of the GT-2 comparison

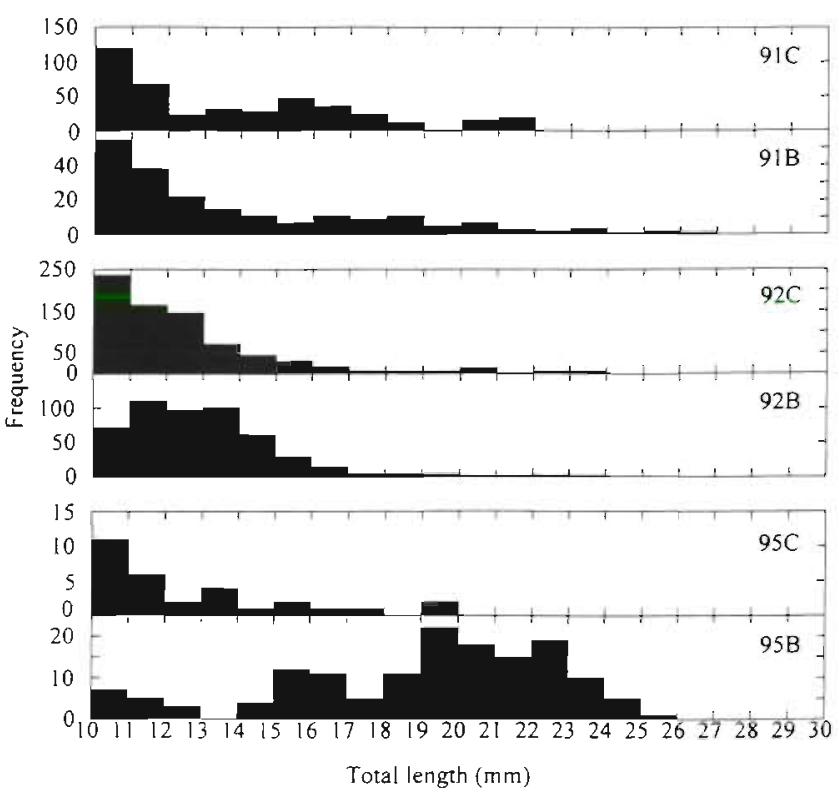

Fig. 7. Euphausia pacifica. Adult length-frequency distributions for Barkley Sound and offshore COPRA sampling stations. Labels indicate year and sampling location (B; Barkley Sound; C: COPRA stations)

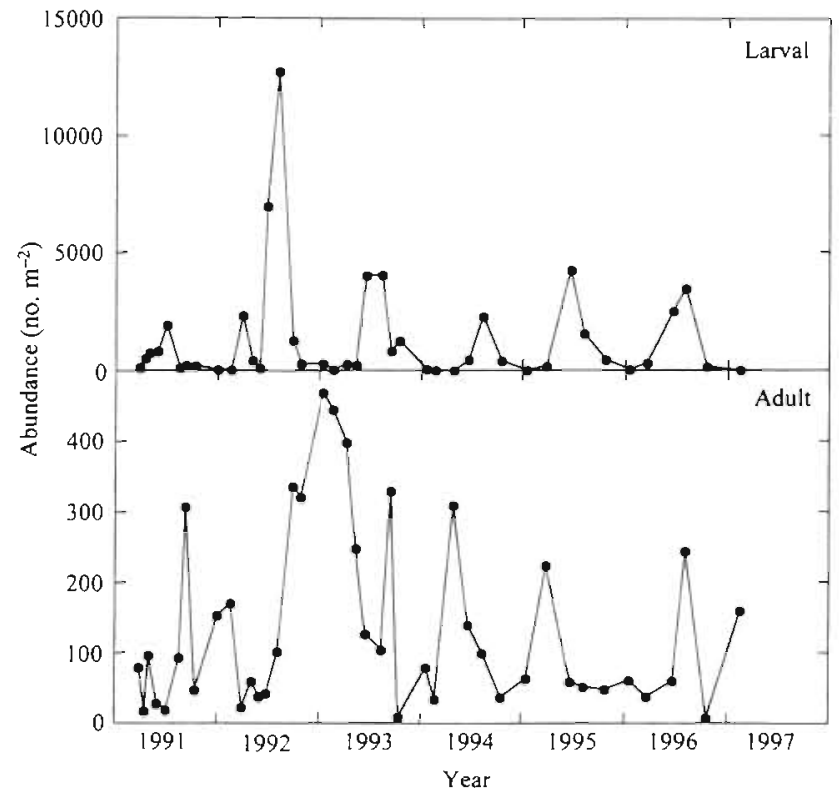

Fig. 8. Euphausia pacifica. Larval and adult abundance

test showed that regression slopes did not differ significantly ( $p>0.05)$. Therefore, I compared the intercepts by using the mean mass adjusted for the grand mean length $(17 \mathrm{~mm})$. The seasonal trend in adjusted mean mass shows a reduction in length-specific mass every winter, Results of a 1-way analysis of variance (ANOVA) showed that adjusted mean mass differed between years $(p<0.003)$. A subsequent comparison of means using Tukey's test (Wilkinson et al. 1996) indicated that this was because the adjusted group mean mass in 1996 ( $7.0 \mathrm{mg}$ ) was significantly $(\mathrm{p}<0.02)$ greater than those for 1991 (5.8 $\mathrm{mg}$ ) and 1992 (6.0 mg). However, the biological significance of such a difference is questionable.

\section{Reproduction}

I investigated interannual variations in reproductive characteristics by examining the biological character-

Table 2. Euphausia pacifica. Mean annual abundances (no. $\mathrm{m}^{-2}$ ) for larvae and adults

\begin{tabular}{|lrc|}
\hline Year & Larvae & Adults \\
\hline $1991-92$ & 479 & 101 \\
$1992-93$ & 2723 & 204 \\
$1993-94$ & 1205 & 197 \\
$1994-95$ & 537 & 114 \\
$1995-96$ & 1303 & 88 \\
$1996-97$ & 1286 & 102 \\
\hline
\end{tabular}



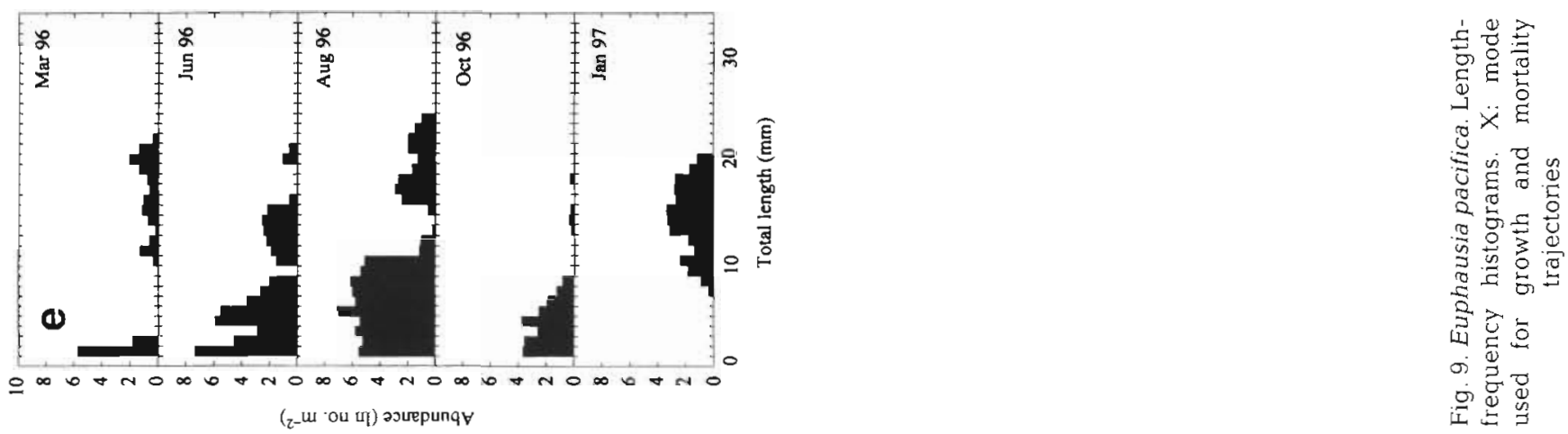

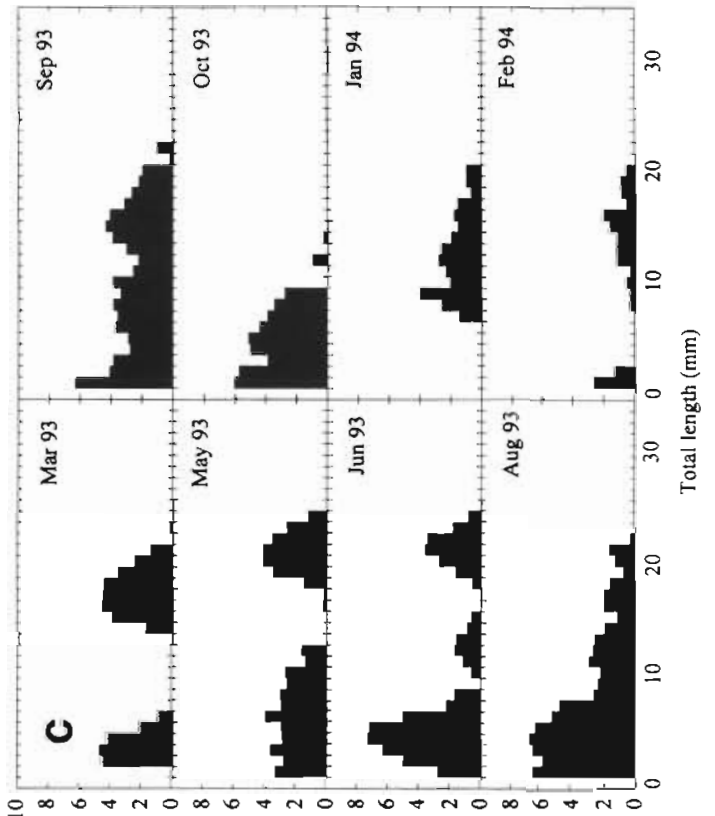

( 2 - U 'ou पl) วsuepunq

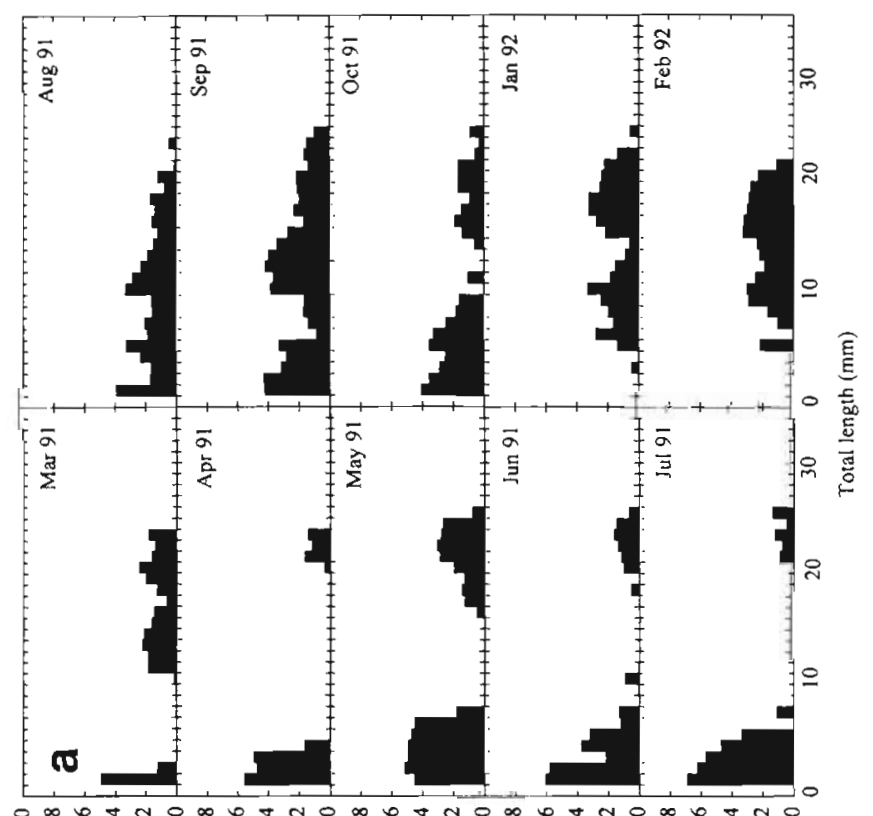

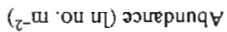
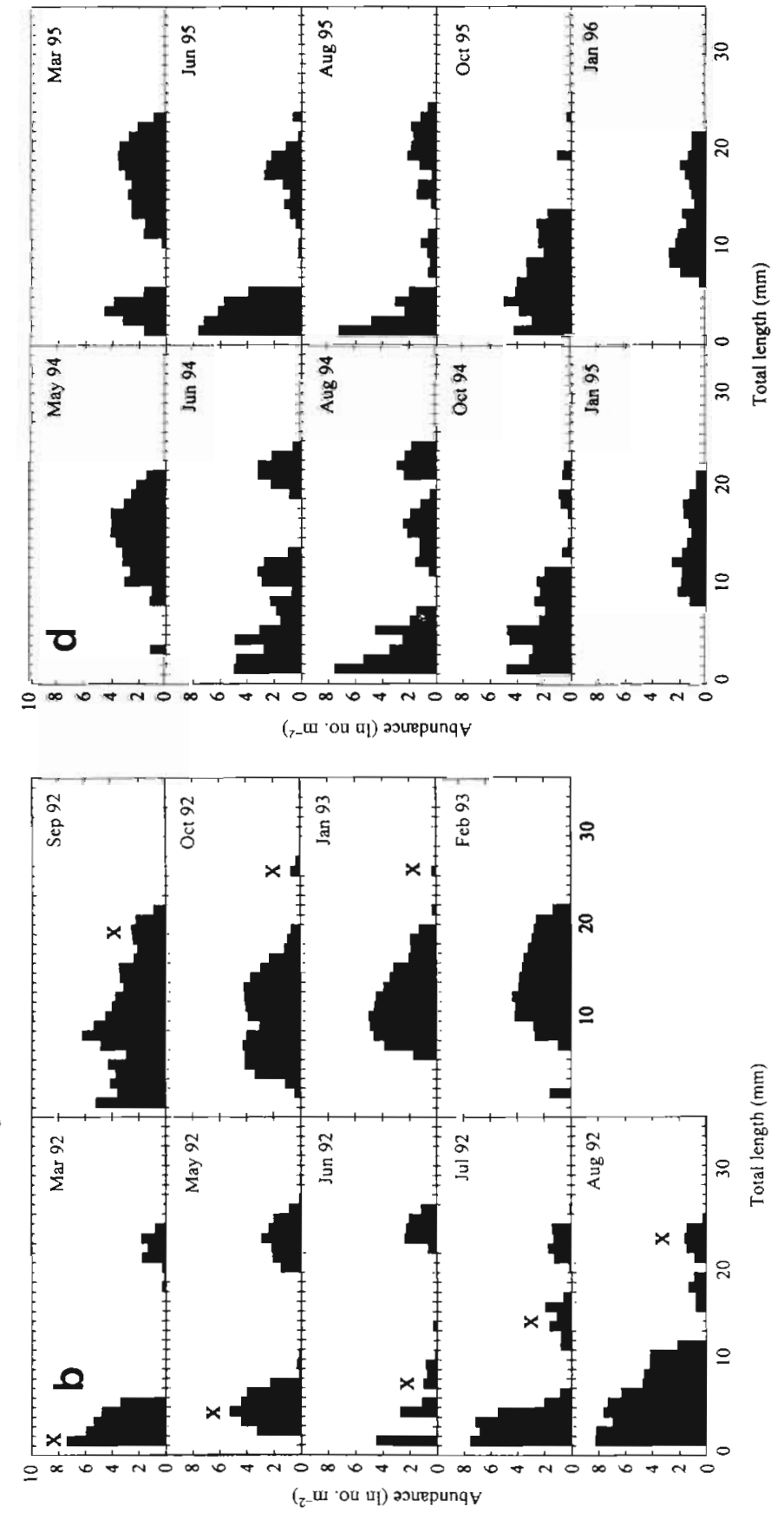


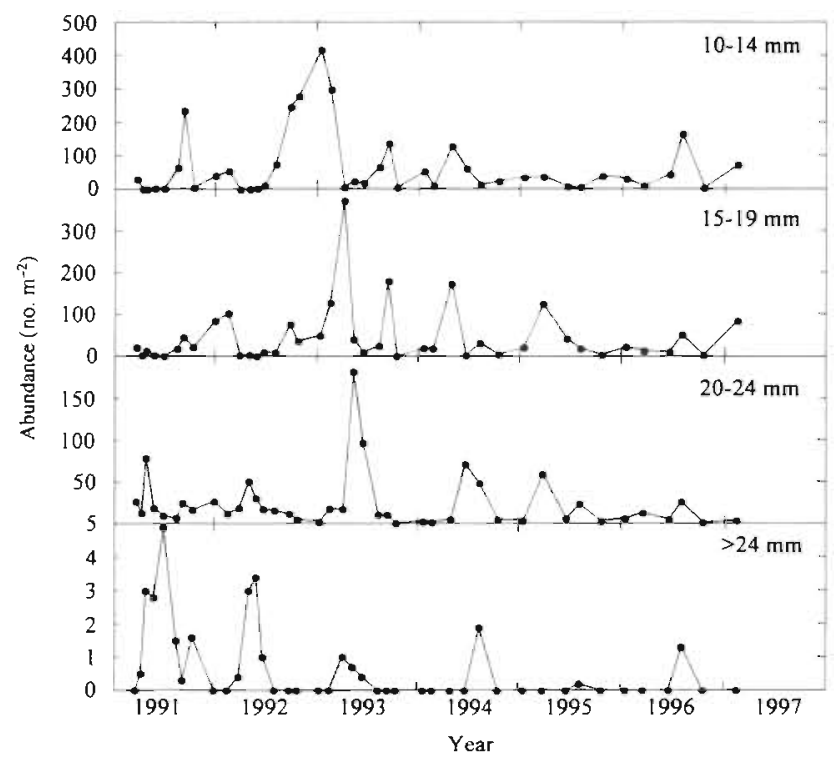

Fig. 10. Euphausia pacifica. Abundance of adults in arbitrary size categories

istics of the parents, spawning itself, the relationship between larval and parental abundances, and the size of larvae.

\section{Adult reproductive characteristics}

The reproductive characteristics of the adults varied seasonally but not interannually. Sex ratios, expressed as the proportion of adults which were male, are presented in Fig. 13. Results of a 1-way ANOVA detected no difference $(p=0.59)$ in sex ratio between years. The grand mean sex ratio over the study period was 0.56 . The seasonal and interannual variation in length-atmaturity, defined as the median length of mature euphausiids, is presented in Fig. 14. In most years (excluding 1992), there is a progressive increase in length-at-maturity over a year. In addition, there appeared to be interannual differences. I tested the effect of the apparent change in length-at-maturity by comparing observed adult abundances with those estimated using the month-specific length-at-maturity data for 1991 (Fig. 15). It appears that variations in length-at-maturity were too small to have any effect on adult abundance.

Fig. 16 shows the year-specific ovarian mass - total mass relationships. There appears to be no relationship between total mass-specific ovarian mass and maturity stage. In other words, there was no tendency for unfertilised, fertilised or gravid females to have low or high mass-specific ovarian mass. Ross et al. (1982) reported that Euphausia pacifica releases

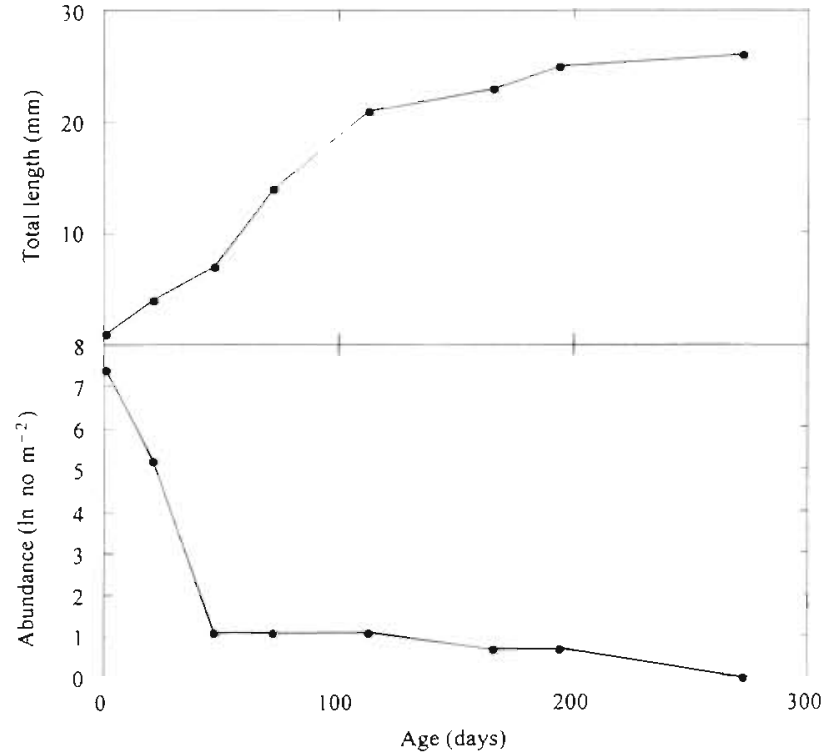

Fig. 11. Euphausia pacifica. Growth and mortality trajectories

broods of eggs. Therefore, I assumed that the upper limit of the data distribution defined maximum sizespecific ovarian mass, in other words, ripe ovarian mass before any broods were released. I estimated ovarian mass at specific total mass values along the upper limit of the distribution to generate the dataset for calculating year-specific maximum ovarian mass -

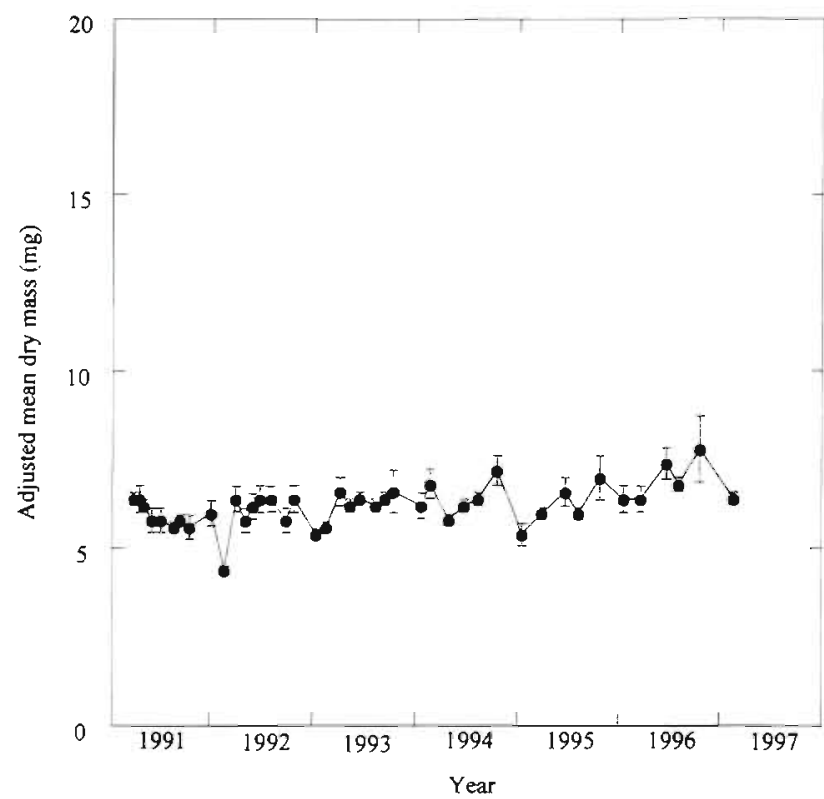

Fig. 12. Euphausia pacifica. Total dry mass adjusted for the grand mean adult length $(17 \mathrm{~mm})$. Error bars are $95 \% \mathrm{com}-$ parison limits 


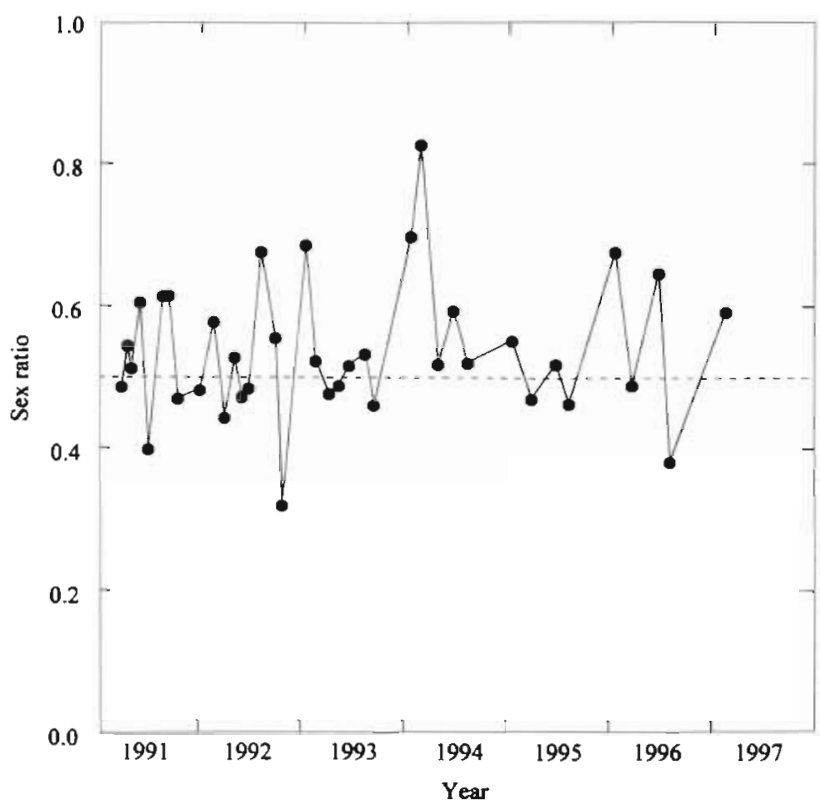

Fig. 13. Euphausia pacifica. Sex ratios (prop. male)

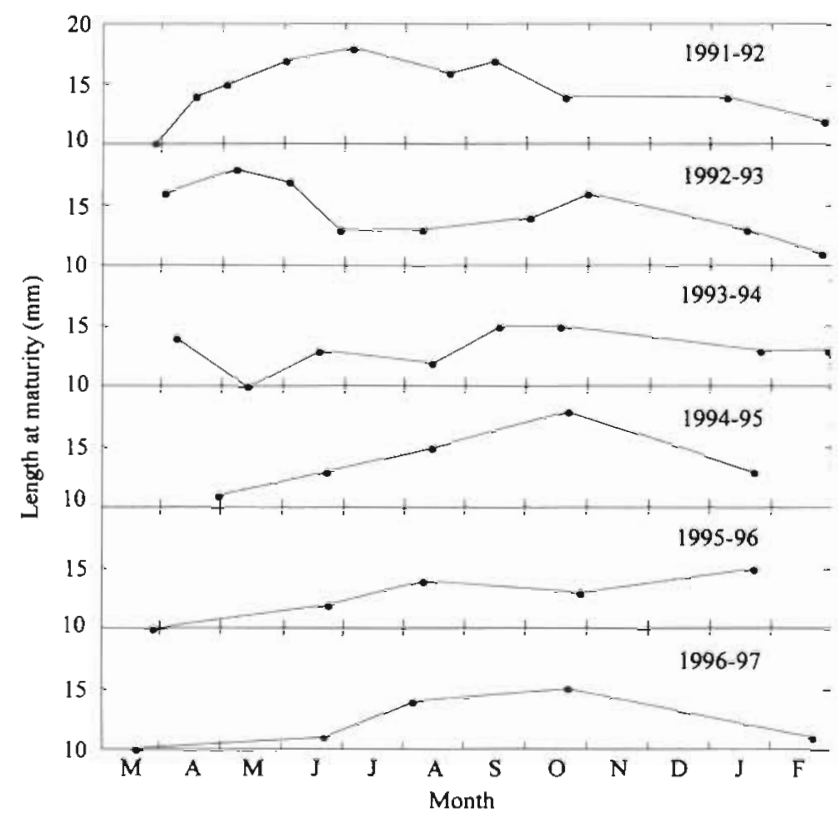

Fig. 14. Euphausia pacifica. Seasonal variation in length-atmaturity

intensity of sampling confounds delineating spawnings after 1993 because, retrospectively, it was determined that the interval between sampling events was longer than the entire subadult phase for Euphausia pacifica. However, there was no apparent change in spawning pattern between 1991, the pre-ENSO year, and 1992 and 1993, the warm water years.

\section{Spawning}

Seasonal and interannual variation in proportion of males and females with spermatophores are shown in Fig. 17. The overall spawning season, as defined by the period when females bore spermatophores, was March through October in all years. Results of 1-way ANOVAs, using arcsine-transformed proportions, indicated no significant effect of year on the proportion of males $(\mathrm{p}=0.46$, mean $=0.88)$ or females $(p=0.92$, mean $=0.16$ ) with spermatophores over the spawning season.

Fig. 18 shows the discrete spawning as defined by the back-calculated birthdates of larvae. Between 1991 and 1993, there were 2 or 3 protracted spawnings over the March-October period and some very restricted spawnings in $\mathrm{No}$ vember and December. The reduced

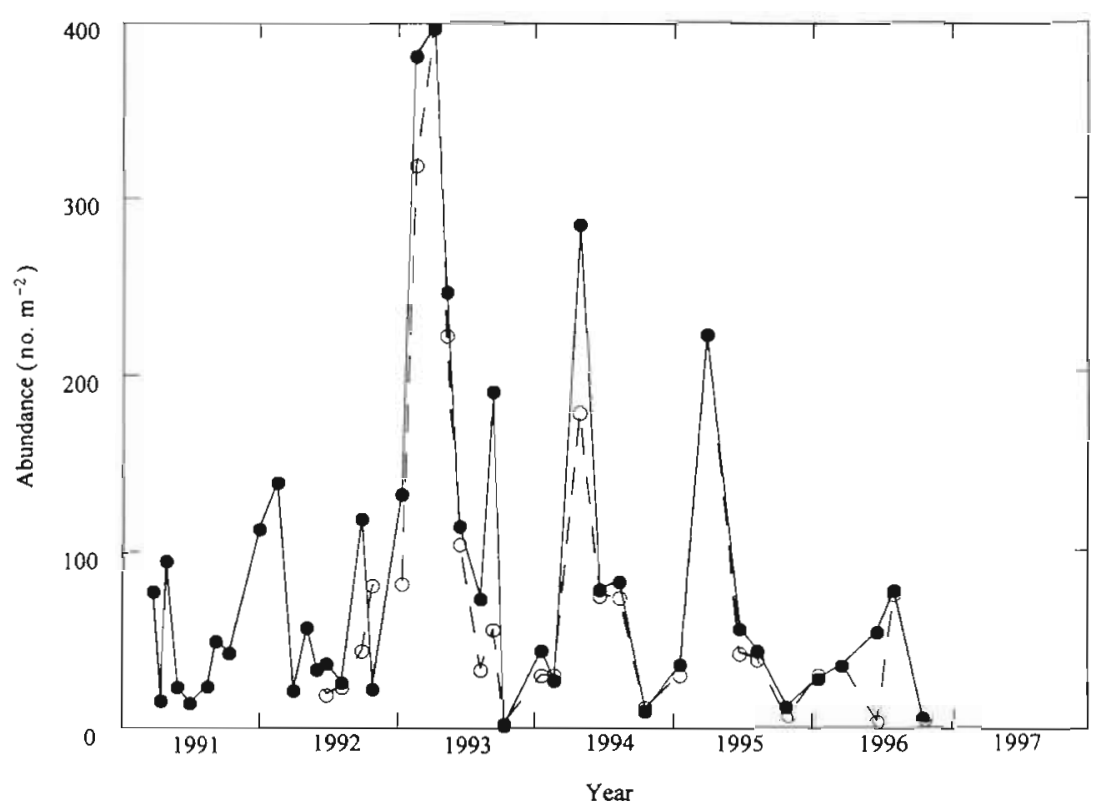

Fig. 15. Euphausia pacifica. Abundance of adults using observed length-at-maturity (O) and that for the 1991-92 sampling year $\bullet$ 


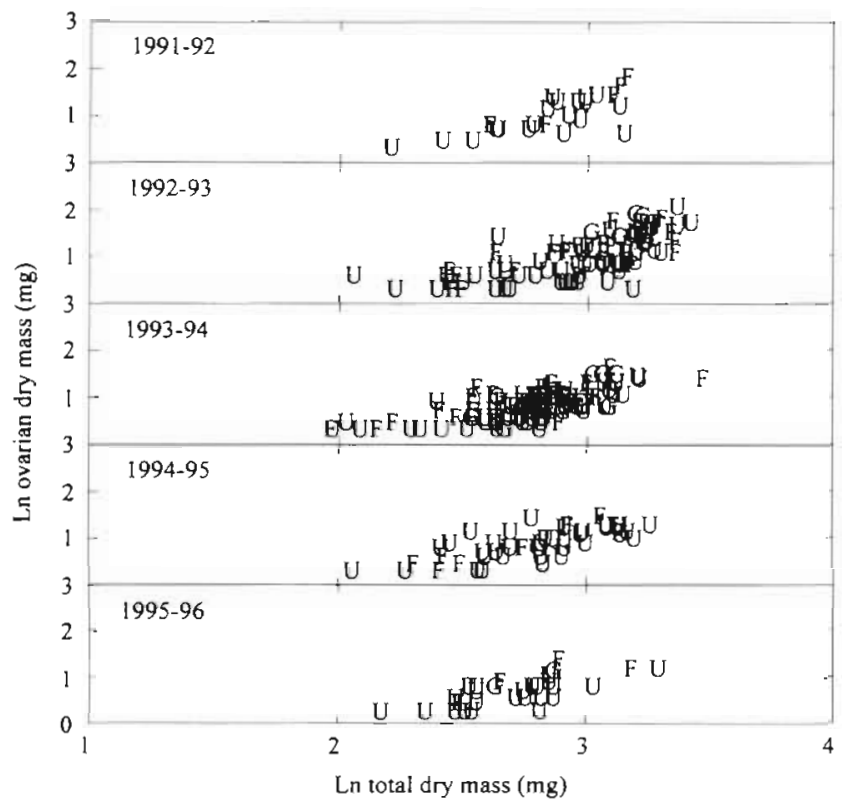

Fig. 16. Euphausia pacifica. Scatterplots of ovarian dry mass versus total dry mass. U: unfertilized. F: fertilized. G: gravid

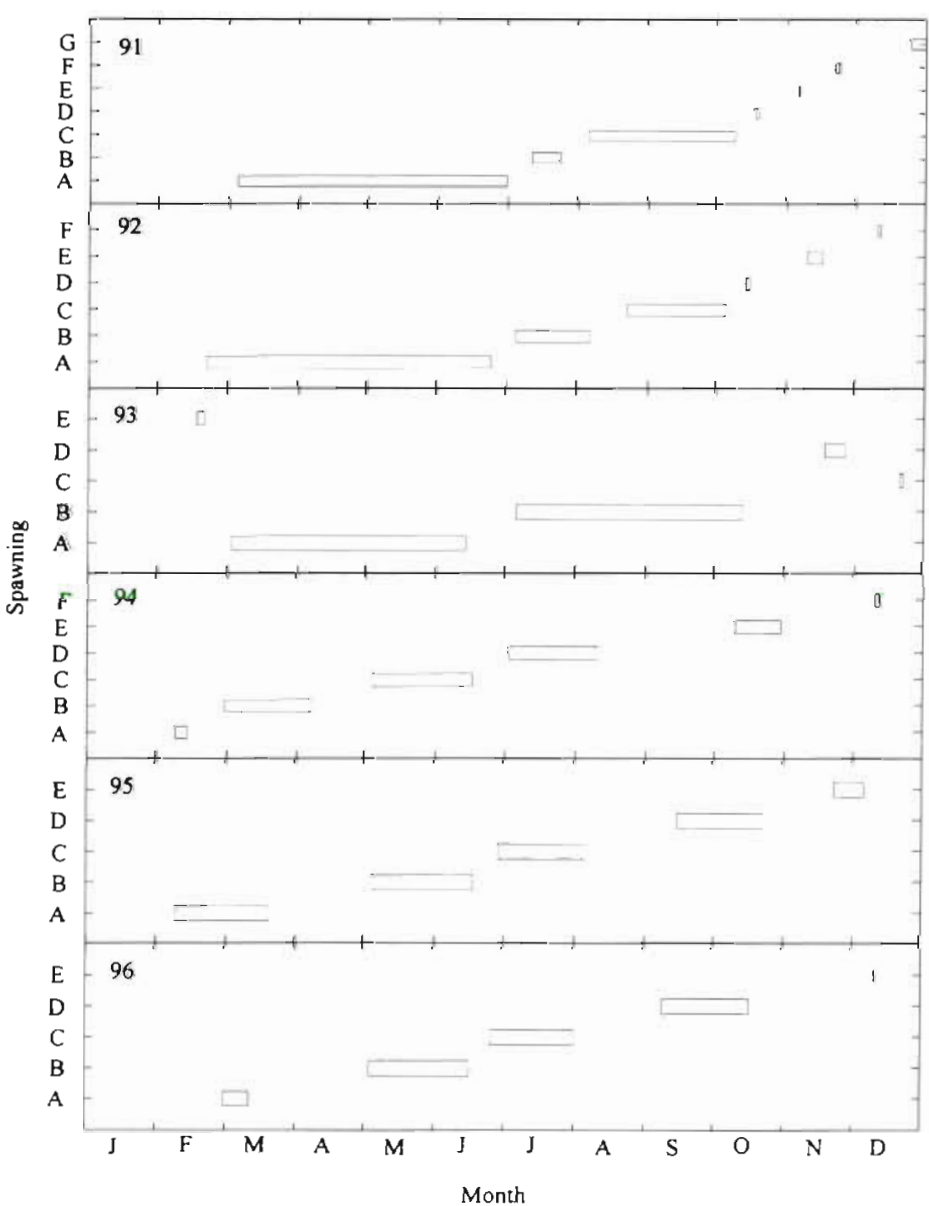

Fig. 18. Euphausia pacifica. Timıng and duration of spawns

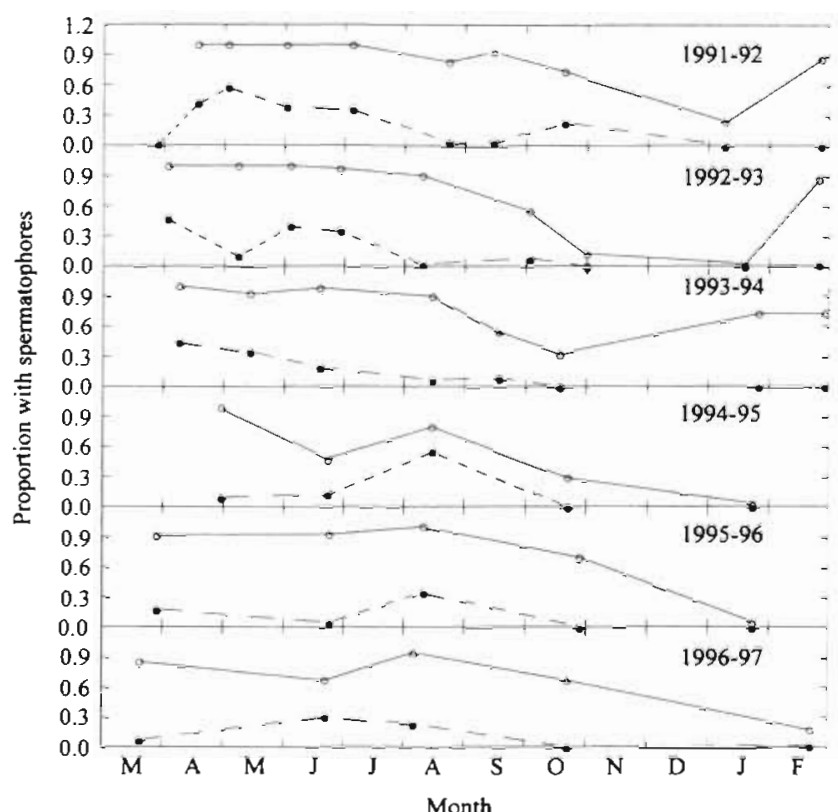

Fig. 17 Euphausia pacifica. Proportion of males (0) and females $(\bullet$ ) with spermatophores

\section{Stock-recruit relationship}

I used the estimates of adult abundance, sex ratio and maturity ogives to estimate the abundance of female parents over the study period (Fig. 19). Mean annual female parent abundances were $29,37,62,48,34$ and $28 \mathrm{~m}^{-2}$ for 1991 through 1996 respectively. I could describe the relationship between parental and larval abundances using the Ricker stockrecruit relationship (Fig. 20). The equation was:

$$
R=304 \times P \times \mathrm{e}^{-0.05 \% P}, \mathrm{p}<0.001, \mathrm{R}^{2}=0.06
$$

where $R$ and $P$ are recruit (larval) and parental abundances respectively.

\section{Larval size}

Mean total length of each larval stage is presented in Fig. 21 There appeared to be no seasonality in mean larval. size for any stage. Results of 1-way ANOVAs showed no significant difference between years ( $p>0.17$ at least) for any larval stage.

\section{Biomass and productivity}

Larval biomass fluctuated over the study period (Fig. 22). It showed peaks in 1992, 1993 
Table 3. Euphausia pacifica. Parameter estimates for ovarian mass - total mass regressions where ln ovarian mass $=a \times \ln$ total mass $+b$

\begin{tabular}{|lcc|}
\hline Year & $a$ & $b$ \\
\hline $1991-92$ & 2.20 & -5.10 \\
$1992-93$ & 1.50 & -3.00 \\
$1993-94$ & 1.39 & -2.57 \\
$1994-95$ & 1.16 & -2.06 \\
$1995-96$ & 2.00 & -4.39 \\
\hline
\end{tabular}

and again in 1996. Adult biomass in 1992 and 1993 was 1.2 and 2 times greater respectively than in 1991 (Fig. 22, Table 4). It has since declined and in 1996 was 0.8 times the pre-ENSO level.

Production trends (Fig, 23, Table 4) were similar to those for biomass. Larval productivity was highest in 1992 and 1996. Moult production accounted for 0.15 (1991) to 0.20 (1996) of total larval production. Adult production was high in 1992 and 1993; it was 1.8 and 2.3 times greater than in 1991 Moult production ranged for 0.40 (1995) to 0.58 (1993) of total adult productivity. Larval growth $P: B$ ratios appeared to be the most variable. Population $P: B$ ratios fluctuated between 10.7 and 23.3, in concert with the proportion of the biomass accounted for by larvae.

\section{DISCUSSION}

The results of this study show that the productivity of Euphausia pacifica along the southwest coast of Vancouver Island varies considerably interannually. It is difficult to compare these results with other studies because no previous study has examined interannual variability in euphausiid productivity. Additional difficulties include the variety of units used to express productivity, as well as what type of production (growth, moult, egg) is used to estimate it. There are surprisingly few studies of euphausiid production. Lindley (1978, $1980,1982)$ estimated the production of a number of species in the North Atlantic. However, he cautioned repeatedly that his samples were collected within the top $10 \mathrm{~m}$ of the water column and therefore he had no indication of how representative samples were of the species he was studying. Stuart \& Pillar (1988) estimated the productivity of E. Iucens in the southern Benguela Current. They concluded that productivity was remarkably high and that the study

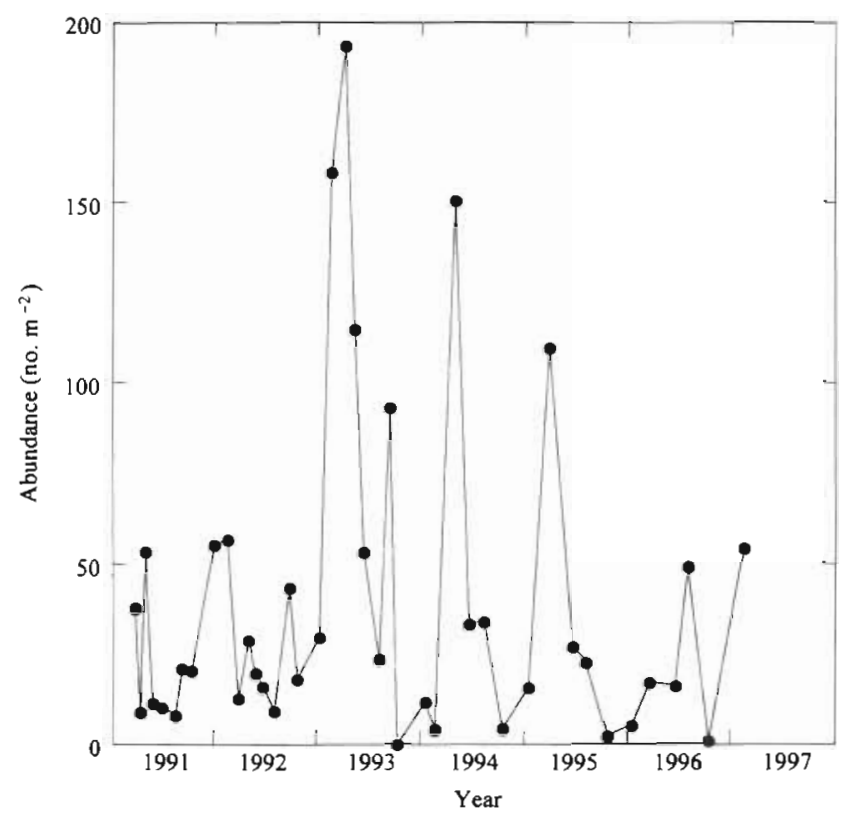

Fig. 19. Euphausia pacifica. Abundance of females

area was a region of high secondary productivity. They presented estimates for inshore, offshore and intermediate regions. I calculated weighted mean productivity and $P: B$ ratio estimates, using biomass as the weighting factor. I calculated production rates of 155, 215 and

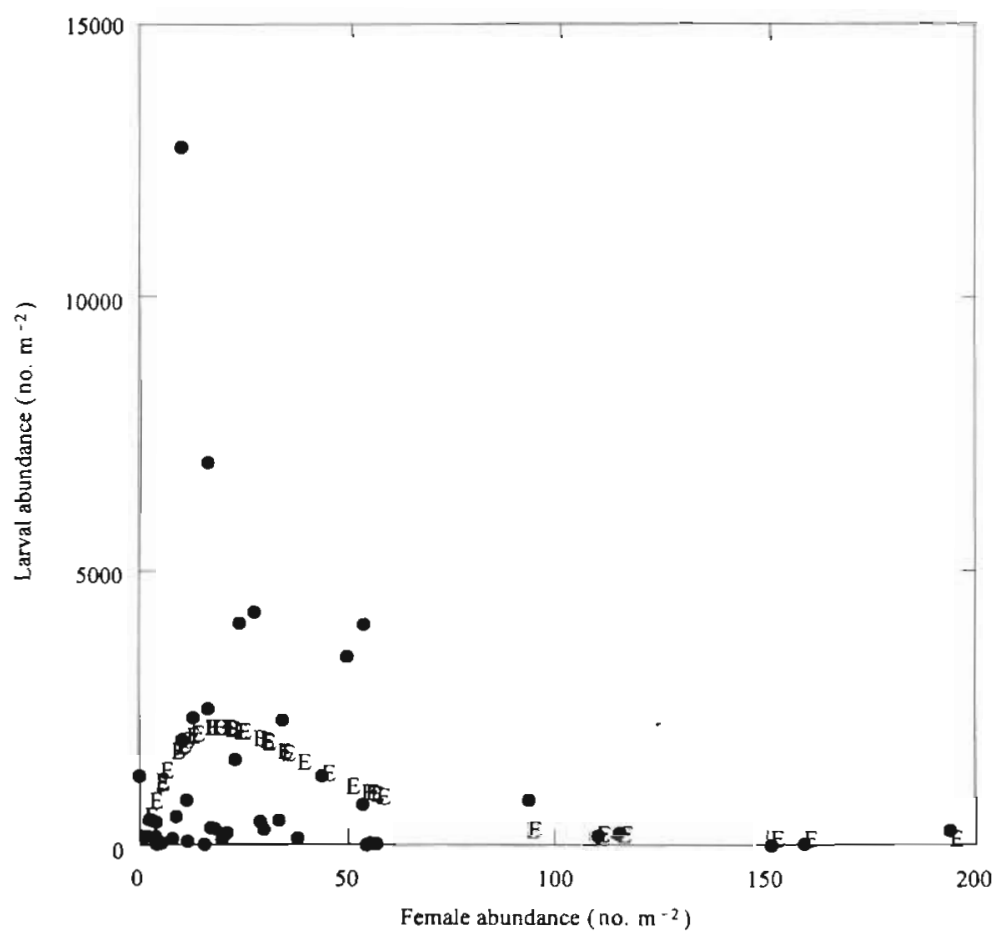

Fig. 20. Euphausia pacifica. Scatterplot of female and larval abundances. E: estimated values based on a fit to the Ricker stock-recruit function 

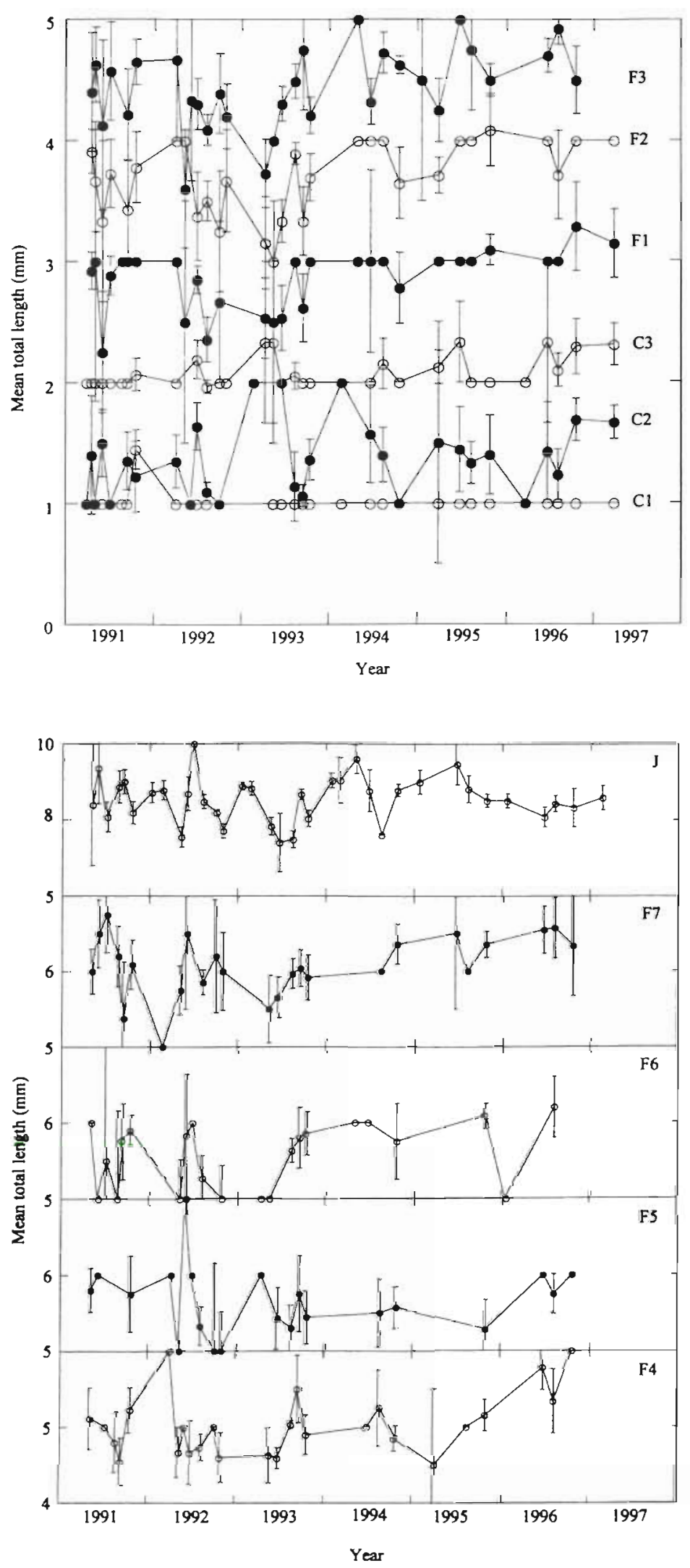

Fig. 21. Euphausia pacifica. Variations in larval size (mean \pm 2 SE)
$10 \mathrm{~m}$ s dry mass $\mathrm{m}^{-3} \mathrm{yr}^{-1}$ for growth, moult and egg production respectively with an overall $P: B$ of 11.5 . By using the average tow depth of $100 \mathrm{~m}, \mathrm{I}$ converted the growth and moulting production estimates for E. pacifica in Barkley Sound to 45-165 and 29-93 mg dry mass $\mathrm{m}^{-3}$ $\mathrm{yr}^{-1}$ and estimated a $P: B$ of 16.8 over all years. Ritz \& Hosie (1982) and Hosie \& Ritz (1983) studied the productivity of Nyctiphanes australis in Storm Bay, Tasmania. Total production (growth. moult and egg production) was estimated as $125 \mathrm{mg}$ dry mass $\mathrm{m}^{-3} \mathrm{yr}^{-1}$ with a $P: B$ of 23.1. Most recently, Lavaniegos (1995) examined the total production of $N$. simplex in Mexican waters. Lavaniegos reported $28 \mathrm{mg}$ dry mass $\mathrm{m}^{-3} \mathrm{yr}^{-1}$ for growth, moult and egg production and a $P: B$ of 17 . Several productivity studies considered growth only. I found that the growth $P: B$ for $E$. pacifica ranged between 4.5 and 6.9 , over all years, and averaged 5.8 . Gomez-Gutierrez et al. (1996) estimated a growth production of $273 \mathrm{mg}$ dry mass $\mathrm{m}^{-2} \mathrm{yr}^{-1}$ (P:B7.0) for $N$. simplex in Baja California, Mexico, waters. Berkes (1977) reported that the growth production of Thysanoessa raschii in the Gulf of St. Lawrence was $1.8 \mathrm{mg}$ dry mass $\mathrm{m}^{-3} \mathrm{yr}^{-1}$ with a $P: B$ of 3.8 .

I purposely ignored estimating egg production. Ross et al. (1982) reported that Euphausia pacifica can produce a large number of broods during the spawning season. However, the relationship they provide between brood size and maternal mass indicates that brood size is poorly estimated. In addition, as pointed out by Stuart \& Nicol (1986) and Stuart (1992), fecundity (annual egg production) also considers the number of broods produced, and the number of broods released by a female in nature is unknown. Ross et al. (1982) have been criticised because it is physiologically improbable that egg production at the rate they estimate is sustainable (Pillar \& Stuart 1988). On the other hand, Stuart (1992) examined egg production by $E$. lucens in the laboratory. The conclusion was that egg production by $E$. Iucens, and perhaps by many other euphausiid species, is considerably higher than previously thought. Because of this uncertainty surrounding egg production, I chose to be conservative and not to consider it in the productivity estimates I calculated.

Although it is of interest to compare productivity estimates among different populations, it is the interannual variation in euphausid productivity which is crucial. The importance of 


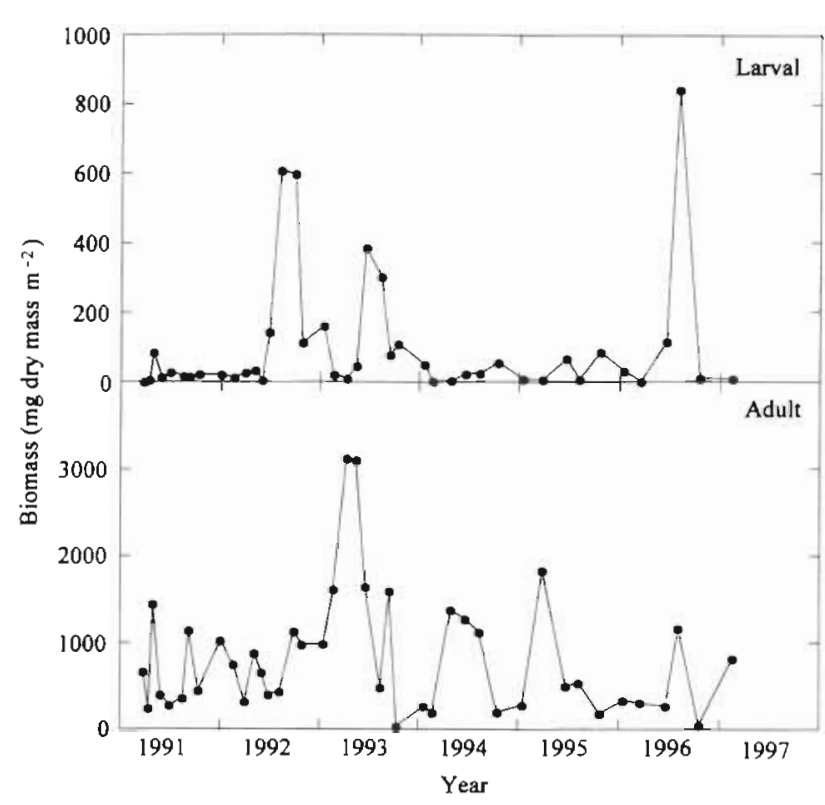

Fig. 22. Euphausia pacifica. Larval and adult biomass

euphausiids to energy flow in a vast number of ecosystems has been commented on, yet no previous study has examined the interannual variability in euphausiid productivity. The comparisons made above are in fact questionable because if these other populations go through the same interannual variability I reported for Euphausia pacifica then, without knowing if these other populations are in high or low productivity states, comparisons are essentially meaningless. The productivity of $E$. pacifica along the southwest coast of Vancouver Island varied considerably over the study period. Larval productivity increased by a factor of 8 in 1992, remained high in 1993, fell roughly by a factor of 4 over the next 2 years and in 1996 was comparable to the 1992 and 1993 high years. Adult total production doubled in 1992 , was about 3 times the 1991 value in 1993 and declined to pre-ENSO levels in 1996.

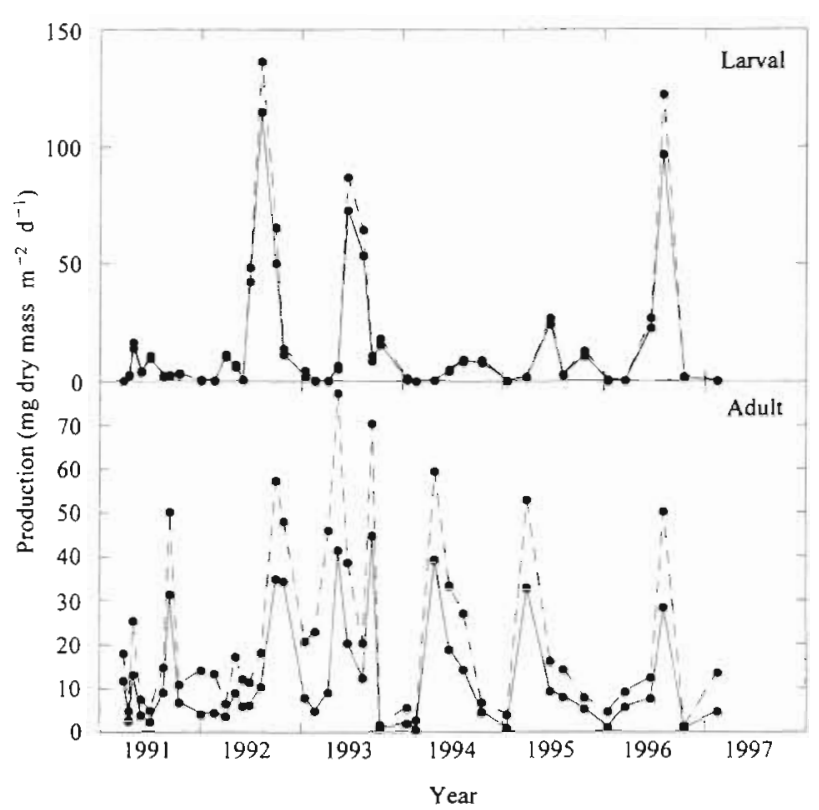

Fig. 23. Euphausia pacifica. Larval and adult production. Dotted line indicates contribution of moults to total production

As indicated by Stuart \& Pillar (1988), I found that the size composition of a euphausiid population can have a considerable effect on its production characteristics. Even though there are some interannual differences in $P: B$ ratios for growth and moulting, most of the variation in population $P: B$ values appears to be a consequence of variations in the proportion of the population which is larval. The $P: B$ ratios overall were much higher for larval growth. Therefore, changes in larval abundance (because I assume growth was not influenced; see below) essentially drive the overall $P: B$ ratio for the population. Lavaniegos (1995) reported that larvae accounted for most of the somatic production for Nyctiphanes simplex, except in the fall; $1-7 \mathrm{~mm}$ size classes contributed $93 \%$ of the total production. Ross (1982a) reported that weight-specific production in Euphausia pacifica decreased with increasing mass after C3. She concluded that E. pacifica conformed

Table 4. Euphausia pacifica. Mean annual biomass (mg dry mass $\mathrm{m}^{-2}$ ), production ( $\mathrm{mg}$ dry $\mathrm{mass}^{\mathrm{m}} \mathrm{m}^{-2} \mathrm{yr}^{-1}$ ) and $P: B$ ratios. Population $P: B$ values were calculated using the sums of biomass and productivity for larvae and adults

\begin{tabular}{|c|c|c|c|c|c|c|c|c|c|c|c|c|c|}
\hline \multirow{3}{*}{ Year } & \multirow{3}{*}{ Biomass } & \multicolumn{5}{|c|}{ Larvae } & \multirow{3}{*}{ Biomass } & \multicolumn{5}{|c|}{ Adults } & \multirow{3}{*}{$\begin{array}{c}\text { Population } \\
P: B\end{array}$} \\
\hline & & \multicolumn{3}{|c|}{ Production } & \multicolumn{2}{|c|}{$P: B$} & & \multicolumn{3}{|c|}{ Production } & \multirow{2}{*}{\multicolumn{2}{|c|}{$\begin{array}{c}P: B \\
\text { Growth Moult }\end{array}$}} & \\
\hline & & Growth & Moult & Total & Growth & Moult & & Growth & Moult & Total & & & \\
\hline $1991-92$ & 22 & 1416 & 243 & 1659 & 65.4 & 11.2 & 678 & 3091 & 2710 & 5801 & 4.6 & 4.0 & 10.7 \\
\hline $1992-93$ & 190 & 10769 & 2205 & 12974 & 56.7 & 11.6 & 823 & 5649 & 4780 & 10428 & 6.9 & 5.8 & 23.1 \\
\hline $1993-94$ & 111 & 7894 & 1609 & 9503 & 70.9 & 14.4 & 1340 & 5571 & 7739 & 13310 & 4.2 & 5.8 & 15.7 \\
\hline $1994-95$ & 20 & 1515 & 238 & 1751 & 76.8 & 12.0 & 744 & 4521 & 3239 & 7760 & 6.1 & 4.4 & 12.5 \\
\hline $1995-96$ & 39 & 2442 & 381 & 2823 & 62.8 & 9.8 & 677 & 4390 & 2970 & 7360 & 6.5 & 4.4 & 14.2 \\
\hline $1996-97$ & 195 & 8624 & 2176 & 10800 & 44.2 & 11.1 & 521 & 3329 & 2597 & 5926 & 6.4 & 5.0 & 23.3 \\
\hline
\end{tabular}


with the generalization that there is greater weightspecific production for smaller individuals as compared with larger ones.

I suggest that the enhanced productivity of Euphausia pacifica in 1992 and 1993, the warm water years, was not a consequence of changes in water temperature but due to exceptionally high upwelling in 1992. It appears that a very large and successful cohort was produced in July-August All I report here is simply a strong cohort moving through the population. The results I presented support Brinton's (1976) observation of good recruitments of $E$. pacifica along the southern California coast coinciding with significant upwelling events. The relationship between favourable upwelling and recruitment success may be explained by Ikeda (1984). He reported that larval E. superba have a critical period during which they must be able to feed adequately. Recruitment success could therefore depend on the overlap between such a critical period and phytoplankton levels, which in turn would be dependent on upwelling intensity. Daly (1990) reported that young E. superba larvae were very sensitive to food type and availability; lab experiments showed that the first feeding larvae (calyptopis I) did not survive delayed food availability (Ikeda 1984, Ross \& Quentin 1989, cited in Daly 1990) or when fed small flagellates (Ross et al. 1988, cited in Daly 1990). She suggested that fluctuations in recruitment may be due to small changes in growth rate. This would operate through the interrelationship between growth rate and survival, with good food conditions reducing the amount of time larvae would be expected to be exposed to the highest predation rates

There are few studies (e.g. Brinton 1976) which have monitored abundance over extended periods, and Brinton's work purposely focused on years with minimal variations in sea temperature. Drobysheva (1987) described cyclical changes in Barents Sea euphausiids over a long ( $30 \mathrm{yr}$ ) time period. He concluded that Thysanoessa inermis is influenced by abiotic conditions and $T$. raschii by biotic interrelationships. He suggested that $T$. raschii abundance increased in relatively cold years because of the spatial separation of predators (cod and capelin). Brinton \& Reid (1986) reported marked changes in euphausiid abundances and species compositions in the southern CaliforniaBaja California coastal region. They suggested that these were a consequence of anomalous warming which resulted in more favourable conditions for the more southerly species (e.g. Nyctiphanes simplex). Euphausia pacifica biomass was a factor of 10 lower and $N$. simplex biomass was 5 times greater They reported no change in the biological characteristics of the euphausiids, just changes in abundance. The results of Brodeur \& Pearcy (1992) suggest that this effect extended to Washington at least. Sahrhage (1988) reported the same observation for E. superba. It appears that the situation along the southwest coast of Vancouver Island mirrors that described by Brinton \& Reid. I found no changes in the growth and reproductive characteristics of E. pacifica during the study period. The interannual differences in production appear to be generated by a strong recruitment in the summer of 1992, a period of strong upwelling.

The apparent importance of environmental effects (upwelling) to recruitment success of Euphausia pacifica seems contradictory to the existence of a stockrecruit relationship. However, the Ricker relationship indicated that there is a negative relationship between parental and larval abundances at relatively high parental abundances. This hints at the possibility of cannibalism at higher parental abundances. In addition, Fig. 20 shows that the exceptionally high larval abundance was produced at a relatively low parental abundance. The significant proportionality constant (304), the environmental effect parameter of the Ricker equation, supports the intervening effect of upwelling. Siegel \& Loeb (1995) examined recruitment variability in E. superba. They concluded that recruitment success may ultimately be a consequence of environmental factors (ice cover) rather than krill population characteristics. Brinton (1976) suggested that production of food associated with the upwelling period was important for recruitment success of E. pacifica off southern California; he implied no relationship between spawner and recruit abundances. Siegel \& Loeb (1995) reported no relationship between a krill recruitment index and the previous year's stock density or index. Loeb et al. (1997) found that interannual fluctuations in krill abundance result largely from variations in yearclass success.

As for many other studies which examined the population biology of euphausiids at low- to mid-latitudes, I found it difficult to develop growth trajectories which are biologically realistic. Consequently, I could not examine interannual growth variations because I could not confıdently construct annual growth trajectories. There are 3 major problems. First, there is the difficulty in segregating out multimodal distributions. As discussed below, there is no procedure which does this objectively for euphausiids, although MULTIFAN (see below) shows good promise. The second difficulty is to develop biologically realistic growth trajectories. Only Brinton (1976) has attempted to examine growth and mortality simultaneously so that there would be some confidence that the time series of modes selected to describe growth are biologically realistic because they also generate a biologically reasonable mortality trajectory. Lindley (1982) points out how errors in assign- 
ing modes to 'cohorts' can occur. Finally, one must consider the effect of size-selective predation. Young et al. (1993) described the trophic relationship between krill Nyctiphanes australis and mackerel Trachurus declivis off eastern Tasmania. They reported a strong negative selection for smaller size classes and a strong positive selection of larger krill throughout the study period. Bollens et al. (1992) discussed the implications of sizeselective predation on estimating euphausiid growth. They noted that growth estimates are based on surviving euphausiids. There has been a subtle change in $E$. pacifica size composition along the southwest coast of Vancouver Island which could affect determining growth functions. As shown in Fig. 10, there have been virtually no large E. pacifica (>24 mm) since 1992. In 1992, there was a large increase in the biomass of Pacific hake Merluccius productus, the dominant planktivore. Accompanying the increase in hake was the appearance of jack Trachurus symmetricus and Pacific Scomber japonicus mackerel which have remained. This change in planktivorous fish abundance occurred when the maximum size of E. pacifica decreased. The suggestion here is that size-selective predation is influencing $E$. pacifica size composition and ultimately the growth trajectories derived from the size data.

Variations in length-specific mass suggested that there were no changes in growth. A common statistic used in fisheries science is the condition factor (LeCren 1951) which 'describes the state of well-being' of an animal. I suggest that the lack of interannual variability in the length-specific mass, a substitute for the condition factor, indicates that growth conditions were comparable for Euphausia pacifica over years. However, although my examination of condition shows no differences in mass-at-length, it provides no information on growth rate. Poleck \& Denys (1982) reported an increased growth rate with increasing temperature for E. superba held in the laboratory. They caution that this higher growth rate with increased temperature would only occur with adequate phytoplankton abundances.

It appears that temperature had no specific effect on Euphausia pacifica reproductive characteristics. Sex ratio fluctuated randomly within years and showed no interannual variations. The high proportion of males bearing spermatophores in this study suggests that spermatophore production is rapid and essentially continuous. Mauchline (1980) pointed out that spermatophore attachment may not necessarily result in fertilization; he speculated that spermatophore attachment may be necessary for final oocyte maturation as well. In addition, females moult about every $5 \mathrm{~d}$ and consequently shed spermatophores along with the exuvia. [Stuart [1992] suggests this is why E. lucens males have 2 ripe spermatophores throughout the year.) These points argue in favour of a higher proportion of males. However, the consistent high proportion of males with spermatophores, and the observed equal sex ratio, suggests that spermatophore production provided by an equal number of males is adequate. Mauchline (1980) summarized work on euphausiid sex ratios. He concluded that the male to female ratio in the majority of species throughout most of the year is probably in the range of unity to $0.7: 1.0$. He also points out that because females generally attain a larger size, the sex ratio favours females in the larger size categories. The increase in length-at-maturity appears to reflect the growth of recruit spawners. The temporal trend in size-at-maturity agrees with observations made for E. pacifica in Puget Sound, Washington, by Ross et al. (1982). Their results suggest that females did not mature until the second year of life. Asthorsson (1990) reported that Thysanoessa raschi recruits began developing secondary sexual characteristics in late winter and the reduction of length-at-maturity then in E. pacifica may reflect this as well. In contrast, Pillar \& Stuart (1988) and Gomez (1995) reported a reduction in length-at-maturity over the summer for E. lucens and Nyctiphanes simplex respectively, which suggests an attainment of sexual maturation at a much earlier age. I observed, as did others (e.g. Einarsson 1945, Nemoto 1957), a regression of secondary sexual characteristics in larger euphausiids; however, their relative abundance was apparently too low to affect the maturity ogive. The results I present show that there has been no interannual difference in size-at-maturity. I found no test which would allow me to compare length-at-maturity effectively. Therefore, I plotted parental abundance using the sampling-specific maturity ogive, as well as that for 1991-92. There is virtually no difference in the abundance estimates, suggesting no change in maturity ogives.

The plots of ovarian mass versus total mass support batch spawning in Euphausia pacifica. It appears that ovarian mass has no effect on maturity state. In other words, females with ovarian masses less than the total mass-specific maximum can be fertilized or gravid. This suggests a release of eggs, a maturation of a subsequent batch, followed by refertilization and other spawning, which then reflects Stuart \& Nicol's (1986) suggestion for E. hanseni, E. lucens and Nyctiphanes capensis. Hosie \& Ritz (1983) and Gomez (1995) observed eggs at various stages of maturity in $N$. australis and $N$. simplex respectively.

There also appears to have been no interannual variation in larval size. Le Roux (1976, cited in Mauchline 1980) demonstrated marked annual variation in the body size of 3 calyptopes of Meganyctiphanes norvegica and Nyctiphanes couchi in the Gulf of 
Mariban, France. Huntley \& Brinton (1991) reported location differences in the size of Euphausia superba larvae. They attributed the enhanced rates of development and growth in Gerlache Strait to relatively high chlorophyll concentrations. Brinton \& Townsend (1984) reported similar results in that larval body sizes were small at low chlorophyll concentrations and large at high concentrations. They suggested that there was likely a stronger relationship between larval size and chlorophyll concentrations than for adults because adults can move into favourable water. Einarsson (1945) suggested that latitudinal variations in larval size would be due to growth and development being affected differently by temperature in such a way that larvae grew more rapidly than they moved through developmental stages.

Another important conclusion of this study is that spawnings, by Euphausia pacifica along Vancouver Island at least, are discrete events. (The approach I used was similar to that developed by Spiridonov [1995] for E. superba. However, his objective was to determine the start, end and intensity of annual spawning whereas my goal was to determine if discrete spawnings could be defined.) This means that at least the E. pacifica population along the southwest coast of Vancouver Island has a cohort (age) structure. This has a considerable number of implications. Most important is that mid-latitude euphausiid populations may consist of a number of cohorts of different ages. Therefore, the number of cohorts within a lengthfrequency distribution can be known and biologically realistic growth and mortality trajectories are estimable. All previous studies determined the number of modes subjectively, whether they used probability paper (Cassie 1954) or the procedure developed by Macdonald \& Pitcher (1979). It is unclear how biologically realistic they are because no one has related this back to a number of spawnings in a given year and hence the number of cohorts which should exist. After identifying ranges of birthdates which are statistically different from each other, I put considerable effort into developing a procedure which objectively assigns modes to cohorts. The most promising approach was to use MULTIFAN in a way similar to that described by Baelde (1994) for deep-water royal red prawns HaLiporoides sibogae. MULTIFAN will define specific distributions in a multi-modal length frequency distribution as cohorts (age classes) by assuming von Bertalanfy growth, which is normally assumed for euphausiids, while simultaneously determining the mean and variance of each distribution. The current difficulty to overcome is to modify MULTIFAN so that it can consider that more than 2 cohorts are produced in a year. This work is continuing. The goal is to develop cohort-specific growth and mortality trajectories. I would use these to estimate productivity by acknowledging the cohort structure of southwest coast Vancouver Island euphausiid populations, and then compare the production estimates with those presented here, which are done conventionally and ignore euphausiid cohort structure. The ultimate goal is to determine if the way euphausiid productivity is estimated now, which appears not to be particularly biologically realistic, is biased by ignoring euphausiid age structure. This has considerable implications for understanding euphausiid biology as well as trophic studies and ecosystem models which consider euphausiids.

Because of problems with segregating modes and assigning modes to cohorts over time in a biologically realistic way, I am suspicious of the 'age' assigned to euphausiids by earlier workers. It may still be the case, as Mauchline stated in 1980 for Euphausia superba, that in most euphausiid species, growth rates and longevity are actually still unknown. Therefore, I have avoided comparing growth rates and have not estimated age-at-maturity.

In summary, the results of this study show that the production of Euphausia pacifica along the southwest coast of Vancouver Island varies considerably between years. It appears that it was the strong upwelling in 1992 and the consequential production of an exceptionally strong recruitment, and its movement through the population, that was responsible for the large productivity changes. Some avenues of study in fisheries oceanography include developing ecosystems models. In light of these results, the variation in euphausiid productivity must be considered and quantified before meaningful models of marine ecosystems can be developed.

Acknowledgements. First, I thank Parks Canada for funding most of the work. I thank Bob Redhead, Dan Ware, Melinda Whitaker, Carol Cooper, the staff at the Bamfield Marine Station, and Ulf Baamstedt and the Department of Fisheries and Marine Biology at the University of Bergen for their support and help. I also thank those who took the time to review my work and for their valuable comments. Finally, I dedicate this paper to the memory of John Boom. 'Boomer' was the Research Co-ordinator of the Bamfield Marine Station when he was lost at sea on February 25, 1996. John became a cherished friend over the time we collected my euphausiid samples together I and many others miss him very much. Using his phrasing, John Boom was 'a fine man'

\section{LITERATURE CITED}

Astthorsson A (1990) Ecology of the euphausiids Thysanoessa raschii, $T$. inermis and Meganyctiphanes norvegica in the Isafjord-deep, northwest Iceland. Mar Biol 107:147-157

Baelde P (1994) Growth, mortality and yield-per-recruit of deep-water royal red prawns (Haliporoides sibogae) off eastern Australia, using the length-based MULTIFAN method. Mar Biol 118:617-625 
Berkes F (1977) Production of the euphausiid crustacean Thysanoessa raschii in the Gulf of St. Lawrence. J Fish Res Bd Can 34:443-446

Boden BP (1950) The post-naupliar stages of the crustacean Euphausia pacifica. Trans Am Microbiol Soc 69: 373-386

Bollens SM, Frost BW, Lin TS (1992) Recruitment, growth and diel vertical migrations of Euphausia pacifica in a temperate fjord. Mar Biol 114:219-228

Brinton E (1976) Population biology of Euphausia pacifica off southern California. Fish Bull 74:733-762

Brinton E, Reid JL. (1986) On the effects of interannual variations in circulation and temperature upon euphausiids of the California Current. UNESCO Tech Pap Mar Sci 49: $25-34$

Brinton E, Townsend AW (1984) Regional relationships between development and growth in larvae of Antarctic krill, Euphausia superba, from field samples. J Crust Biol 4(Spec No. 1):224-246

Brodeur RD, Pearcy WG (1992) Effects of environmental variability on trophic interactions and food web structure in a pelagic upwelling ecosystem. Mar Ecol Prog Ser 84: $101-119$

Cassie R M (1954) Some use of probability paper in the analysis of frequency distributions. Aust J Mar Freshwat Res 5: $513-522$

Daly KL (1990) Overwintering development, growth and feeding of larval Euphausia superba in the Antarctic marginal ice zone. Limnol Oceanogr 35:1564-1576

Drobysheva SS (1987) Population characteristics of abundant Barents Sea Euphausiacea. ICES C M 1987/L:12

Einarsson H (1945) Euphausiacea I. North Atlantic species. Dana Rep 27:1-185

Gomez JG (1995) Distribution patterns, abundance and population dynamics of the euphausiuds Nyctiphanes simplex and Euphausia exima off the west coast of Baja California Mexico. Mar Ecol Prog Ser 119:63-76

Gomez-Gutierrez J, DeSilva-Davila R, Laveniegos-Espejo B (1996) Growth production of the euphausiid Nyctiphanes simplex on the coastal shelf off Bahia Magdelena, Baja California Sur, Mexico. Mar Ecol Prog Ser 138:309-314

Hosie GW, Ritz DA (1983) Contribution of moulting and eggs to secondary production of Nyctiphanes australis (Crustacea: Euphausiacea). Mar Biol 77:215-220

Huntley M, Brinton E (1991) Mesoscale variation in growth and early development of Euphausia superba DANA in the western Bransfield region. Deep-Sea Res 8/9: $1213-1240$

Iguchi $N$, Ikeda $T$ (1994) Experimental study on brood size, egg hatchability and early development of a euphausiid Euphausia pacifica from Toyama Bay, southern Japan Sea. Bull Jpn Sea Fish Res Inst 44:49-57

Iguchi $N$, Ikeda T (1995) Growth, metabolism and growth efficiency of a euphausiid crustacean Euphausla pacifica in the southern Japan Sea, as influenced by temperature. J Plankton Res 17:1757-1769

Ikeda T (1984) Development of the larvae of Antarctic krill (Euphausia superba Dana) observed in the laboratory. J Exp Mar Biol Ecol 75:107-117

Jerde CW, Lasker, R (1966) Molting of euphausiid shrimps: shipboard observations. Limnol Oceanogr 11:120-124

Lasker R (1966) Feeding, growth, respiration and carbon utilization of a euphausiid crustacean. J Fish Res Bd Can 23: $1291-1317$

Lavaniegos BE (1995) Production of the euphausiid Nyctiphanes simplex in Vizcaino Bay, Western Baja California. J Crust Biol 15:444-453
LeCren ED (1951) The length-weight relationship and seasonal cycles in gonad condition and weight in the perch. J Anim Ecol 21:201-219

Lindley JA (1978) Population dynamics and production of euphausiids. I. Thysanoessa longicaudata in the North Atlantic Ocean. Mar Biol 46:121-130

Lindley JA (1980) Population dynamics and production of euphausiids. II. Thysanoessa inermis and T. raschii in the North Sea and American coastal waters. Mar Biol 59:225-233

Lindley JA (1982) Population dynamics and production of euphausiids. III. Meganyctiphanes norvegica and NyCtiphanes couchi in the North Atlantic Ocean and the North Sea. Mar Biol 66:37-46

Loeb V, Siegel V, Holm-Hansen O, Hewitt R, Fraser W, Trivelpiece W, Trivelpiece S (1997) Effects of sea-ice extent and krill or salp dominance on the Antarctic food web. Nature 387:897-900

Macdonald PDM, Pitcher TJ (1979) Age-groups from size-frequency data: a versatile and efficient method of analyzing distribution mixtures. J Fish Res Bd Can 36:987-1001

Mauchline J (1980) The biology of mysids and euphausids. Adv Mar Biol 18:1-680

Nemoto $T$ (1957) Foods of baleen whales in the northern Pacific. Sci Rep Whales Res Inst Tokyo 12:33-89

Parsons TR, Maita Y, Lalli CM (1984) A manual of chemical and biological methods for seawater analysis. Pergamon Press, Toronto

Pillar SC, Stuart V (1988) Population structure, reproductive biology and maintenance of Euphausia lucens in the southern Benguela Current. J Plankton Res 10:1083-1098

Poleck TP, Denys CJ (1982) Effects of temperature on the moulting, growth and maturation of Antarctic krill Euphausia superba (Crustacea: Euphausiacea) under laboratory conditions. Mar Biol 70:255-265

Ricker WE (1975) Computation and interpretation of biological statistics of fish populations. Bull Fish Res Bd Can 191

Ritz DA, Hosie GW (1982) Production of the euphausiid Nyctiphanes australis in Storm Bay, south-eastern Tasmania Mar Biol 68:103-108

Ross RM (1981) Laboratory culture and development of Euphausia pacifica. Limnol Oceanogr 26:235-246

Ross RM (1982a) Energetics of Euphausia pacifica. I. Effects of body carbon and nitrogen and temperature on measured and predicted production. Mar Biol 68:1-13

Ross RM (1982b) Energetics of Euphausia pacifica. II. Complete carbon and nitrogen budgets at $8^{\circ}$ and $12^{\circ}$ throughout the lifespan. Mar Biol 68:15-23

Ross RM, Daly KL, English TS (1982) Reproductive cycle and fecundity of Euphausia pacifica in Puget Sound, Washington. Limnol Oceanogr 27:304-314

Sahrhage D (1988) Some indications for environmental and krill resource variability in the Southern Ocean. ln: Sahrhage D (ed) Antarctic Ocean and resources variability. Springer-Verlag, Berlin, p 33-40

Sameoto DD (1976) Respiration rates, energy budgets and moulting frequencies of three species of euphausiids found in the Gulf of St. Lawrence. J Fish Res Bd Can 33: $2568-2576$

Siegel V, Loeb V (1995) Recruitment of Antarctic krill Euphausia superba and possible causes of variability. Mar Ecol Prog Ser 123:45-56

Smiles MC, Pearcy WG (1971) Size structure and growth rate of Euphausia pacifica off the Oregon coast. Fish Bull 69: 79-86

Sokal RR, Rohlf FJ (1981) Biometry. WH Freeman Press, San Francisco

Spiridonov VA (1995) Spatial and temporal variability in 
reproductive timing of Antarctic krill (Euphausia superba DANA). Polar Biol 15:161-174

Stuart V (1992) Fecundity of Euphausia lucens - evidence for multiple broods. J Exp Mar Biol. Ecol 160:221-228

Stuart V, Nicol S (1986) The reproductive potential of three euphausiid species from the southern Benguela region. J Exp Mar Biol Ecol 103:267-274

Stuart V, Pillar SC (1988) Growth and production of Euphausia lucens in the southern Benguela Current. J Plankton Res 10:1099-1112

Summers PL (1993) Life history, growth and ageing of Thysanoessa spinifera. MSc thesis, University of Victoria, Victoria, BC

SYSTAT (1994) SYSTAT for Windows: statistics, Version 5 edn. SYSTAT, Inc, Evanston, IL

Editorial responsibility: Otto Kinne (Editor),

Oldendorf/Luhe, Germany
Tanasichuk RW, Ware DM, Shaw W, McFarlane GA (1991) Variation in the diet, daily ration and feeding periodicity of Pacific hake (Merluccius productus) and spiny dogfish (Squalus acanthias) off the lower west coast of Vancouver Island. Can J Fish Aquat Sci 48:2118-2128

Thomson RE, Ware DM (1996) A current velocity index of ocean variability. J Geophys Res C6:14297-14310

Wilkinson L, Blank G, Gruber C (1996) Desktop data analysis with SYSTAT Prentice Hall, Upper Saddle River, NJ

Young JW, Jordan AR, Bobbi C, Johannes RE, Haskard K. Pullen G (1993) Seasonal and interannual variability in krill (Nyctiphanes australis) stocks and their relationship to the fishery for jack mackerel (Trachurus declivis) off eastern Tasmania, Australia. Mar Biol 116:9-18

Submitted: January 17, 1997; Accepted: April 15, 1998 Proofs received from author(s): October 9, 1998 